\title{
REAL-TIME CYCLE SLIP DETECTION AND REPAIR FOR BDS-3 TRIPLE-FREQUENCY AND QUAD-FREQUENCY B1C/B1I/B3I/B2A SIGNALS
}

\author{
Hao WANG ${ }^{1)}$, Shuguo PAN ${ }^{1)}$ *, Wang GAO ${ }^{1)}$, Fei YE ${ }^{1)}$, Chun MA ${ }^{1)}$, Ju TAO ${ }^{\text {2) }}$ and Yunfeng WANG ${ }^{1)}$ \\ 1) School of Instrument Science and Engineering, Southeast University, Nanjing 210096, China \\ ${ }^{2)}$ XinXing JiHua Science \&Technology Development Co., Ltd. Beijing, 100070, China
}

*Corresponding author's e-mail: psg@seu.edu.cn

\begin{tabular}{|c|c|}
\hline ARTICLE INFO & ABSTRACT \\
\hline Article history: & \multirow{11}{*}{$\begin{array}{l}\text { This paper presents a real-time cycle slip detection and repair strategy for the BDS-3 triple- } \\
\text { frequency and quad-frequency phase observations. For the triple-frequency phase observations, } \\
\text { two EWL code-phase combinations and one GF-phase combination are jointly employed to detect } \\
\text { and repair cycle slips. Based on the different performances in the success of cycle slip detection } \\
\text { and repair, this paper uses GF-phase combinations to detect and repair cycle slip individually. } \\
\text { Specifically, the GF-phase combination with a large MTIV value is applied to detect cycle slip } \\
\text { possessing the stronger ability to resist ionospheric delay. Besides, the GF-phase combination with } \\
\text { a higher success rate of cycle slip repair is selected to repair cycle slip, and the classic LAMBDA } \\
\text { method and Ratio test are implemented to fix the cycle slip solution and evaluate reliability } \\
\text { separately. For the quad-frequency phase observations, we employ a supernumerary EWL } \\
\text { combination based on the triple-frequency, which can directly determine the cycle slip value of } \\
\text { the } 4^{\text {th }} \text { frequency. The results show that the cycle slip estimation value still can detect and repair } \\
\text { all real and artificially added cycle slips even under harsh conditions. Moreover, the overall cycle } \\
\text { slip repair success rate is greater than } 99.99 \% \text {. }\end{array}$} \\
\hline Received 8 March 2021 & \\
\hline Accepted 14 June 2021 & \\
\hline Available online 15 July 2021 & \\
\hline Keywords: & \\
\hline BDS-3 & \\
\hline Triple-frequency signals & \\
\hline Quad-frequency signals & \\
\hline Cycle slip & \\
\hline Code-phase combination & \\
\hline GF-phase combination & \\
\hline
\end{tabular}

\section{INTRODUCTION}

According to the three-step development strategy, China's BeiDou Navigation Satellite System (BDS) has completed the construction of the BeiDou demonstration system (BDS-1) and the BeiDou regional satellite navigation system (BDS-2) in 2003 and 2012 individually. The BeiDou Global Satellite Navigation System (BDS-3) has been available to the global on December 27, 2018, and fully completed by the end of 2020 (Yang et al., 2018; Yang et al., 2020). To ensure a steady transition from the BDS-2 to the BDS-3, the B1I (1561.098 MHz) and B3I (1268.52 MHz) signals of the BDS-2 will continue to be broadcasted, while the B2I signal will be replaced by the B2a (1176.45 MHz) signal of the BDS-3 (Su and Jin, 2019). In addition, BDS-3 introduces several new signals, including B1C (1575.42 MHz) and B2b (1207.14 MHz) (Li et al., 2019a). At present, it is mainly $\mathrm{B} 1 \mathrm{C} / \mathrm{B} 1 \mathrm{I} / \mathrm{B} 3 \mathrm{I} / \mathrm{B} 2 \mathrm{a}$ signals, generally at least three frequencies such as B1I/B3I/B2a signals and $\mathrm{B} 1 \mathrm{C} / \mathrm{B} 3 \mathrm{I} / \mathrm{B} 2 \mathrm{a}$ signals, which can be received by the GNSS receiver.

The most important observation of the Global Navigation Satellite System (GNSS) is phase observation which can achieve centimeter-level or even millimeter-level positioning accuracy. However, due to the limitations of observation conditions, such as external environmental interference and obstruction by obstacles, cycle slips often occur resulting in loss of lock-in phase observations and reinitialization of ambiguity (Li et al., 2019b). Therefore, for high-precision positioning applications, the cycle slips of the original phase observation must be detected and repaired successfully. Otherwise, the positioning accuracy and convergence speed will be reduced. (Bisnath, 2000; Kim and Langley, 2001) presented the algorithm using double-differenced observations to detect and repair cycle slip, which involves using data from both receivers to comprise double-differenced observations. However, this algorithm has a great limitation in that must have two station data.

In the past two decades, the research and application of Precision Point Positioning (PPP) urgently needs a method of detecting and repairing cycle slips effectively which only requires undifferenced observation data from a single station (Zumberge et al., 1997). For dual-frequency observation, the TurboEdit method (Blewitt, 1990) has become the most widely used method for cycle slip detection, which consists of the Hatch-MelbourneWübbena (HMW) combination (Hatch, 1983; Melbourne, 1985; Wübbena, 1985) and the residual ionospheric combination. This method can effectively detect most cycle slip combinations, but the detection effect of cycle slips is poor under active ionospheric conditions. Liu (2011) investigated an improved 
approach to amalgamate ionospheric total electron content (TEC) rate (TECR) with HMW to detect cycle slips. However, this approach assumes that the ionospheric delay change is relatively stable in a short time. In order to overcome the shortcomings of poor performance in detecting cycle slips under active ionospheric conditions, Cai et al. (2013) studied the forward and backward moving window average (FBMWA) method and the second-order, time-difference phase ionospheric residual (STPIR) method which can availably detect cycle-slips under active ionospheric environment. Nevertheless, Yao and Wang (2020) pointed out that GF-IF and the STPIR method lose the ability to successfully detect insensitive cycle slip groups under high active ionospheric conditions. In addition, it is worth noting that Shi et al. (2019) took the code observation error into account by adopting a posterior code residual check which was designed as a priority over the posterior phase residual check so that these cycle slips do not degrade positioning performance even if these cycle slips were not correctly detected in the pre-processing stage.

All satellites of the BDS-2 have the ability to broadcast triple-frequency signals and the BDS-3 has introduced two additional signals. Zhang and $\mathrm{Li}$ (2016) stated clearly the benefits of the third frequency signal for cycle slip correction compared with the dual-frequency signals. Li et al. (2017) indicated that the availability of triple-frequency can provide a more flexible way to establish the combinations with longer wavelength, lower combined noise, and weaker ionospheric delay. This method can decrease the noise of observations and the influence of the ionosphere on cycle slip detection and repair. On this basis, Yao et al. (2019) analyzed the effects of different combined ways of observation on cycle slip detection performance and the success rate of repair and gave an optimal combination way. Considering the impact of ionospheric delay, Zhao et al. (2015) implemented three linearly independent extra-wide-lane (EWL), wide-lane (WL), and narrow-lane (NL) jointly to determine the corresponding cycle slip by the three cascaded steps. Besides, a method was proposed to use two EWL combinations and one GF combination to detect and repair cycle slip, and applied previous observation without cycle slip to predict the ionosphere and correct the accuracy of the GF combination (Yao et al., 2016). Nevertheless, these methods inevitably increase combination noise error for cycle slip detection. To solve this problem, Liu et al. (2018), Chang et al. (2018), Li et al. (2019), and Yao et al. (2019) proposed different ionospheric prediction models to modify combined observations and enhance its accuracy improving the success rate and reliability of cycle slip detection and repair, especially for low sampling rate data under the active ionospheric circumstance. Similarly, based on the correlation between the epoch-differenced phases and the predicted ionospheric delay, an error model was put forward to adaptively tune the model error variance online and correct the observations, improving the accuracy of estimating the cycle slip value on NL observation (Qian et al., 2020). With respect to fixing cycle slip, Zeng et al. (2018) employed two GF-IF combinations and the code-phase linear combinations with B3 carrier phase observations to confirm the cycle slip on the original three carriers and utilized the corresponding fixed criteria with the threshold judgment and minimum one norm to validate the cycle slip candidates and finally get the correct one. However, this method becomes unreliable due to the reduction of the rounding success rate under the condition of the active ionosphere. Hence, Huang et al. (2016), Zangeneh-Nejad et al. (2017), Li et al. (2019), and Deng et al. (2019) applied a combination of two GF combinations and one EWL combination to detect cycle slip and employed the classic Least-square Ambiguity Decorrelation Adjustment (LAMBDA) method, which can determine the optimal candidate of cycle slip estimation value to fix cycle slip. Nevertheless, the above-mentioned theories are based on the observation of BDS-2 for cycle slip detection and repair without considering the applicability of BDS-3.

Compared to BDS-2, BDS-3 satellites broadcast two new open service signals B1C and B2a which are compatible and interoperable with other GNSS (Wang et al., 2019; Fan, et al., 2020). Although some scholars have performed cycle slip detection and repair based on the BDS-3 triple-frequency and quad-frequency observations, they do not fully consider the impact of ionospheric delay and choose the optimal combination way leading to weak sensitivity of cycle slip detection and low success rate of cycle slip repair (Yang et al., 2019; Zhang, et al., 2019; Shi, et al., 2020). Therefore, this paper adopts the following strategy to deal with the BDS-3 data. For the triple-frequency observation, a new combination consisted of EWL code-phase combination and GF-phase combination is introduced, and the optimal selected way of combination observation is analyzed. Because the GF-phase combination has a large different performance in cycle slip detection and repair, so they must be processed separately. In this paper, the window smoothing method is used to predict the real-time ionospheric variation which can update the GF-phase combinations, and the LAMBDA method is used to fix the cycle slip estimation value of the original phase observations. Based on the fixed cycle slip of the triple-frequency phase observation, the third EWL combination is initiated to detect and fix the fourth frequency cycle slip value.

The rest of this paper is organized as follows: In Section 2, the relevant mathematical methodology is presented. In Section 3, the data collection and experiment design are described. Besides, the experiments under different scenarios are carried out. The conclusions of this paper will be given in Section 4. 


\section{METHODOLOGY}

This paper focuses on the analysis of the cycle slip detection and repair model about the BDS-3 triple-frequency B1I/B3I/B2a signals and $\mathrm{B} 1 \mathrm{C} / \mathrm{B} 3 \mathrm{I} / \mathrm{B} 2 \mathrm{a}$ signals. Concerning the quad-frequency signal, it is only necessary to combine an additional EWL combination based on the triple-frequency signals to obtain the cycle slip value on the fourth frequency.

\subsection{CODE-PHASE LINEAR COMBINATION}

Based on the original triple-frequency observations, the linear combinations of carrier phase observations and code observations in meter can be defined as follows:

$$
\begin{aligned}
\Phi_{i j k} & =\frac{i f_{1} \Phi_{1}+j f_{2} \Phi_{2}+k f_{3} \Phi_{3}}{i f_{1}+j f_{2}+k f_{3}}= \\
& =\rho+T-\eta_{i j k} I_{1}-\lambda_{i j k} N_{i j k}+\varepsilon_{i j k} \\
P_{a b c} & =a \rho_{1}+b \rho_{2}+c \rho_{3}=\rho+T+\eta_{a b c} I_{1}+\varepsilon_{a b c}
\end{aligned}
$$

where $\Phi_{i j k}$ and $P_{a b c}$ are the combined phase and code observations in meter; $(i, j, k)$ represents the coefficient of phase observations; $(a, b, c)$ is the coefficient of code observations and $a+b+c=1$, which ensures that the geometrical distance is invariant. Meanwhile, we set $a=b=c=1 / 3$ to minimize the combined code noise (Huang et al., 2016) in this paper; $f$ denotes the frequency of phase observation; $T$ is tropospheric delay error, and $I_{1}$ is the first-order ionospheric delay on the first frequency; Parameters $N_{i j k}, \eta_{i j k}$ and $\eta_{a b c}$, represent the combined ambiguity, ionospheric amplification factor of phase and code observations, respectively. $\varepsilon_{i j k}$ and $\varepsilon_{a b c}$ mean combined noise.

To eliminate the geometric distance and tropospheric delay, the linear combination of code observation minus phase observation is widely used, referred to as a code-phase combination. Simultaneously, the difference is generally made between adjacent epochs to eliminate the influence of errors such as satellite orbits and satellite clock errors, and the combined cycle slip estimation value is constructed as follows:

$$
\Delta N_{i j k}=\frac{\Delta P_{a b c}}{\lambda_{i j k}}-\Delta \Phi_{i j k}-\eta_{i j k, a b c} \Delta I_{1}
$$

where $\eta_{i j k, a b c}$ is the ionospheric amplification factor, $\eta_{i j k, a b c}=\eta_{i j k}+\eta_{a b c} ; \quad \eta_{i j k, a b c} \Delta I_{1}$ denotes the residual ionospheric variation. The corresponding standard deviation (STD) of the combined cycle slip estimation value can be expressed as the following formula:

$$
\begin{aligned}
& \sigma_{\Delta N_{j j k}}= \\
& =\sqrt{2\left(i^{2}+j^{2}+k^{2}\right) \sigma_{\varepsilon}{ }^{2}+2\left(a^{2}+b^{2}+c^{2}\right)\left(\sigma_{p} / \lambda_{i j k}\right)^{2}+\left(\eta_{i j k, a b c} \sigma_{\Delta \Delta_{1}}\right)^{2}}
\end{aligned}
$$

where $\sigma_{\varepsilon}, \sigma_{p}, \sigma_{\Delta I_{1}}$ denote the observation noise of the phase, code, and the first frequency ionospheric variation between epochs. $\sigma_{\varepsilon}$ is generally 0.01 cycle, and $\sigma_{p}$ depends on the elevation angle taking the maximum value as $0.5 \mathrm{~m}$ in this paper (Yang et al., 2018). $\sigma_{\Delta I_{1}}$ depends on the level of ionospheric activities, generally less than $0.15 \mathrm{~m}$ (even if the ionosphere is active) (Liu, 2011). The corresponding rounding success rate can be expressed as the following equation:

$$
P\left(\left|\Delta \hat{N}_{i j k, a b c}-\operatorname{round}\left(\Delta N_{i j k, a b c}\right)\right| \leq 0.5\right)=2 \Phi\left(\frac{1}{2 \sigma_{\Delta N_{i j k, a b c}}}\right)-1
$$

where $\Phi(x)=\int_{-\infty}^{x} \frac{1}{\sqrt{2 \pi}} \exp \left(-\frac{1}{2} z^{2}\right) d z, \Delta \hat{N}_{i j k, a b c}$ denotes the theoretical value; round ( ) means rounding.

Equations (4) and (5) demonstrate that the selected combined observation possessing the excellent characteristics of longer wavelength, smaller ionospheric amplification coefficient, and lower noise can greatly improve the rounding success rate of combined cycle slip estimation value.

We search through the combination coefficients within the range from -5 to 5 cycles and select the combination coefficients for B1I/B3I/B2a and $\mathrm{B} 1 \mathrm{C} / \mathrm{B} 3 \mathrm{I} / \mathrm{B} 2 \mathrm{a}$ signals that satisfy the sum of combination coefficients $S=0$ (Here, $S$ is the sum of combination coefficients $i, j, k$ ), long wavelength, small ionospheric amplification factor, and low combined observation noise ( $\mathrm{Li}$ et al., 2017). Table 1 shows the optimal EWL combinations, which are used to detect and repair cycle slip with the combination coefficients $(1,-4,3)$ and $(0,1,-1)$ that are named as $\mathrm{EWL}_{1}$ and $\mathrm{EWL}_{2}$ combinations. In addition, we can clearly see that the sum of the combination coefficients for the optimal EWL combination is zero, so none of the EWL combinations mentioned above can effectively detect the insensitive cycle slip group $\Delta N_{1}=\Delta N_{2}=\Delta N_{3}$ (also known as the equivalent cycle slip group).

Similarly, for BDS-3 quad-frequency observations (B1C/B1I/B3I/B2a signals), the optimal EWL combination is shown in Table 2. Compared to the triple-frequency observations in Table 1 , the quadfrequency observations in Table 2 can assemble more combined observations with the excellent characteristics mentioned above. According to the solution result of Equation (5), the rounding success rate is infinitely close to $100 \%$ for the third EWL combination, which is called $\mathrm{EWL}_{3}$ in this paper.

Figure 1 shows the rounding success rate of the phase combination with $\mathrm{EWL}_{1}$ and $\mathrm{EWL}_{2}$ for $\mathrm{B} 1 \mathrm{I} / \mathrm{B} 3 \mathrm{I} / \mathrm{B} 2 \mathrm{a}$ signals and $\mathrm{B} 1 \mathrm{C} / \mathrm{B} 3 \mathrm{I} / \mathrm{B} 2 \mathrm{a}$ signals respectively to repair cycle slip under different ionospheric conditions when the code noise is $0.5 \mathrm{~m}$. As shown in Figure 1, the rounding success rate of the combination of $\mathrm{EWL}_{1}$ and $\mathrm{EWL}_{2}$ is still greater than $99.99 \%$, even under the highly active ionospheric condition that the STD of ionospheric variation 
Table 1 BDS-3 triple-frequency optimal EWL combinations *.

\begin{tabular}{|c|c|c|c|c|c|c|c|c|}
\hline \multirow{2}{*}{ Signal } & \multirow{2}{*}{$i$} & \multirow{2}{*}{$j$} & \multirow{2}{*}{$k$} & \multirow{2}{*}{ Wavelength/m } & \multirow{2}{*}{ Ionospheric amplification factor } & \multicolumn{3}{|c|}{ The combined noise $/ \mathrm{m}$} \\
\hline & & & & & & $\sigma_{\Delta \mathrm{I}}=0 \mathrm{~m}$ & $\sigma_{\Delta \mathrm{I}}=0.1 \mathrm{~m}$ & $\sigma_{\Delta \mathrm{I}}=0.2 \mathrm{~m}$ \\
\hline \multirow{3}{*}{$\mathrm{B} 1 \mathrm{I} / \mathrm{B} 3 \mathrm{I} / \mathrm{B} 2 \mathrm{a}$} & 1 & -4 & 3 & 18.316 & 0.381 & 0.075 & 0.085 & 0.107 \\
\hline & $\mathbf{0}$ & 1 & -1 & 3.256 & -0.064 & 0.127 & 0.127 & 0.128 \\
\hline & 1 & -3 & 2 & 2.765 & 0.317 & 0.157 & 0.160 & 0.169 \\
\hline \multirow{3}{*}{$\mathrm{B} 1 \mathrm{C} / \mathrm{B} 3 \mathrm{I} / \mathrm{B} 2 \mathrm{a}$} & 1 & -4 & 3 & 9.768 & -0.409 & 0.083 & 0.092 & 0.117 \\
\hline & $\mathbf{0}$ & 1 & -1 & 3.256 & -0.067 & 0.127 & 0.127 & 0.128 \\
\hline & 1 & -5 & 4 & 4.884 & -0.476 & 0.124 & 0.133 & 0.156 \\
\hline
\end{tabular}

* The bold combination coefficients represent the combinations used in this paper and the same below.

Table 2 BDS-3 quad-frequency optimal EWL combinations.

\begin{tabular}{|c|c|c|c|c|c|c|c|c|c|}
\hline \multirow[t]{2}{*}{ Signal } & \multirow[t]{2}{*}{$h$} & \multirow[t]{2}{*}{$i$} & \multirow[t]{2}{*}{$j$} & \multirow[t]{2}{*}{$k$} & \multirow{2}{*}{$\begin{array}{c}\text { Wavelength/ } \\
\mathrm{m}\end{array}$} & \multirow{2}{*}{$\begin{array}{c}\text { Ionospheric } \\
\text { amplification factc }\end{array}$} & \multicolumn{3}{|c|}{ The combined noise $/ \mathrm{m}$} \\
\hline & & & & & & & $\sigma_{\Delta \mathrm{I}}=0 \mathrm{~m}$ & $\sigma_{\Delta \mathrm{I}}=0.1 \mathrm{~m}$ & $\sigma_{\Delta \mathrm{I}}=0.2 \mathrm{~m}$ \\
\hline \multirow{3}{*}{$\mathrm{B} 1 \mathrm{C} / \mathrm{B} 1 \mathrm{I} / \mathrm{B} 3 \mathrm{I} / \mathrm{B} 2 \mathrm{a}$} & 1 & -1 & 0 & $\mathbf{0}$ & 20.932 & 0.016 & 0.026 & 0.026 & 0.026 \\
\hline & 0 & 1 & -4 & 3 & 18.316 & 0.382 & 0.075 & 0.077 & 0.084 \\
\hline & -1 & 2 & -4 & 3 & 146.526 & 0.366 & 0.077 & 0.080 & 0.086 \\
\hline
\end{tabular}

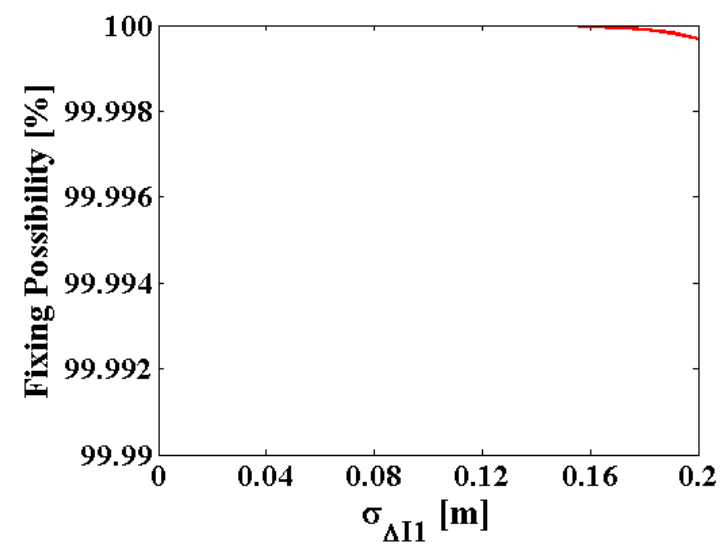

(a) EWL 1 combination for B1I/B3I/B2a signals

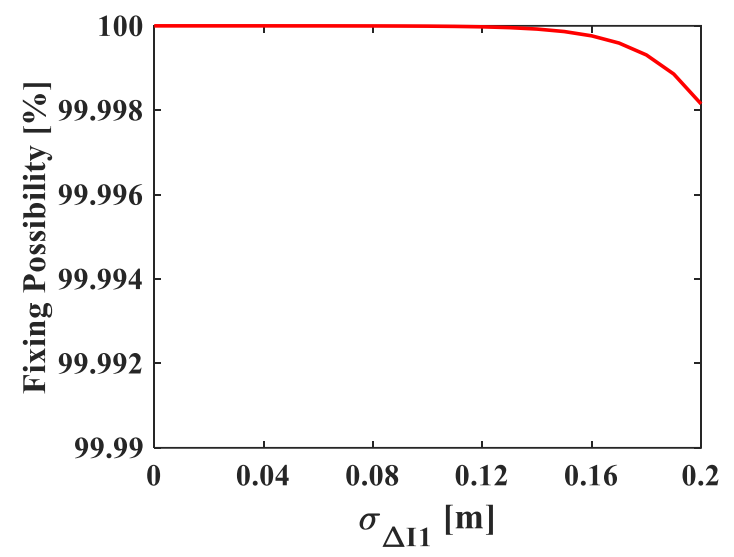

(c) EWL 1 combination for $\mathrm{B} 1 \mathrm{C} / \mathrm{B} 3 \mathrm{I} / \mathrm{B} 2 \mathrm{a}$ signals

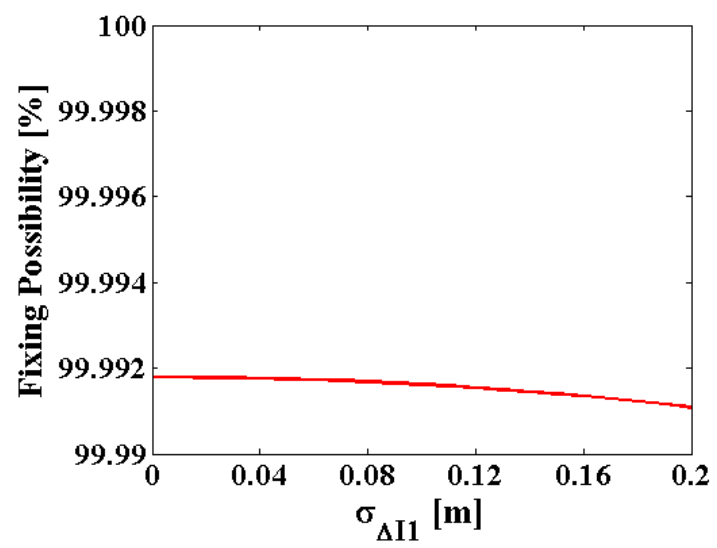

(b) EWL 2 combination for B1I/B3I/B2a signals

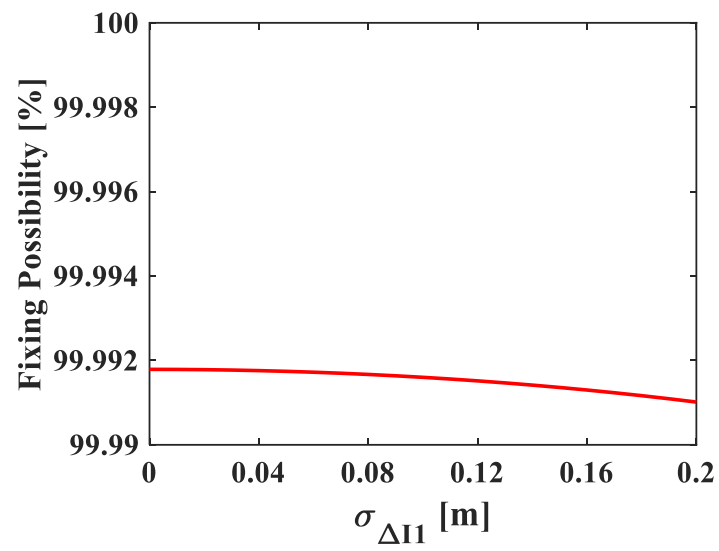

(d) EWL2 combination for B1C/B3I/B2a signals.

Fig. 1 The rounding success rate of the phase combination with $\mathrm{EWL}_{1}$ and $\mathrm{EWL}_{2}$ for B1I/B3I/B2a signals and $\mathrm{B} 1 \mathrm{C} / \mathrm{B} 3 \mathrm{I} / \mathrm{B} 2 \mathrm{a}$ signals respectively under different ionospheric conditions (the code noise is $0.5 \mathrm{~m}$ ).

reaches $0.15 \mathrm{~m}$. Therefore, it can be considered that the EWL code-phase combination is completely correct by rounding.

In some research, the first-order ionospheric delay is eliminated by setting the code observation coefficient for the EWL combination (Cai et al., 2013).
Figure 2 shows the rounding success rate of $\mathrm{EWL}_{1}$-IF and $\mathrm{EWL}_{2}$-IF for B1I/B3I/B2a signals under different code noise conditions. The success rate of the $E_{1}$-IF and $E_{2 W L}$-IF combinations using this method is much lower than the strategy in Figure 1, especially for the $\mathrm{EWL}_{1}$-IF combination, under the 


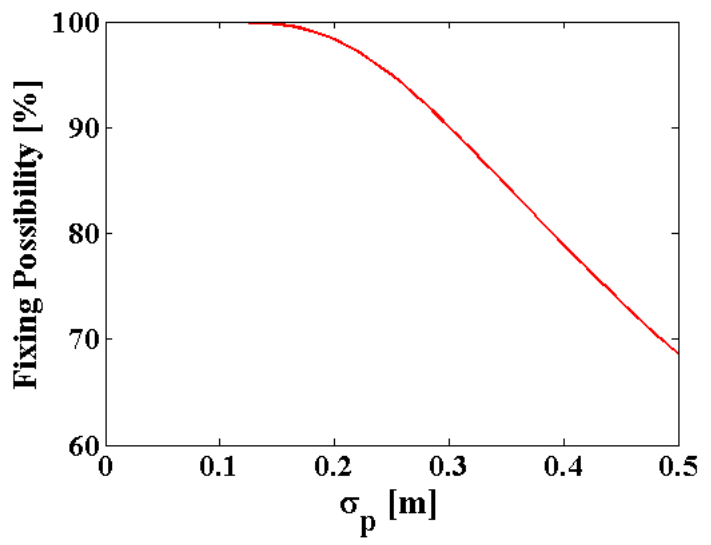

(a) EWL1-IF combination

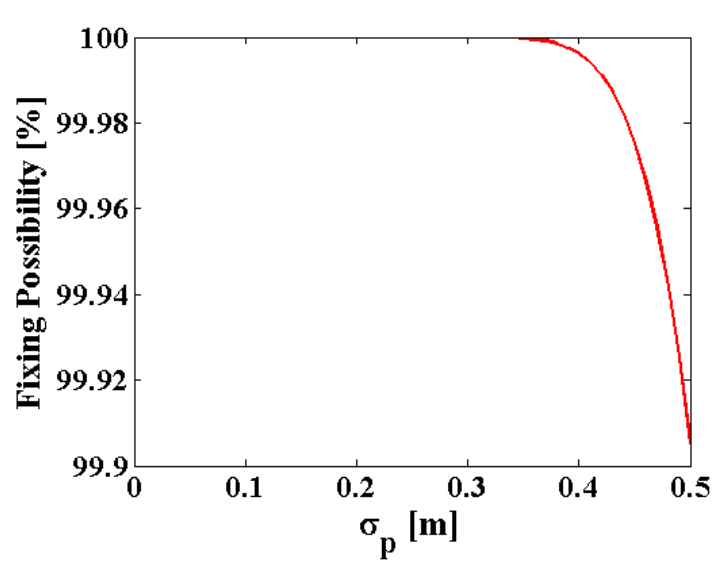

(b) EWL2-IF combination

Fig. 2 The Rounding success rate of EWL - IF and EWL - IF combinations for B1I/B3I/B2a signals under different code noise conditions.

condition of low code observation noise. The main reason is that the combined code noise is amplified after the EWL combination adopts the IF combination. For example, the code observation coefficient $(a, b, c)$ of the $\mathrm{EWL}_{1}$-IF combination is $(10.184,-1.738$, -7.446), which greatly amplifies the combined noise, although the first-order ionospheric delay is eliminated. Therefore, it is very difficult to determine the combined cycle slip estimation value only based on a single epoch. However, the algorithm introduced in this paper can overcome this defect.

\subsection{GF-PHASE COMBINATIONS}

The GF-phase combination is constructed as follows (Tang et al., 2017):

$$
\left\{\begin{array}{l}
\Phi_{\alpha \beta \gamma}=\alpha \lambda_{1} \Phi_{1}+\beta \lambda_{2} \Phi_{2}+\gamma \lambda_{3} \Phi_{3}=-N_{\alpha \beta \gamma}-\eta_{\alpha \beta \gamma} I_{1}+\varepsilon_{\alpha \beta \gamma} \\
N_{\alpha \beta \gamma}=\alpha \lambda_{1} N_{1}+\beta \lambda_{2} N_{2}+\gamma \lambda_{3} N_{3} \\
\eta_{\alpha \beta \gamma}=\alpha \lambda_{1}+\beta \lambda_{2} \frac{f_{1}}{f_{2}}+\gamma \lambda_{3} \frac{f_{1}}{f_{3}}
\end{array}\right.
$$

Ignoring the influence of other errors and making a difference between adjacent epochs, the combined time-differenced ambiguity can be obtained which is the so-called combined cycle slip estimation value and its STD can be expressed as:

$$
\begin{aligned}
& \Delta N_{\alpha \beta \gamma}=-\Delta \Phi_{\alpha \beta \gamma}-\eta_{\alpha \beta \gamma} \Delta I_{1} \\
& \sigma_{\Delta N_{\alpha \beta \gamma}}=\sqrt{2\left(\alpha^{2}+\beta^{2}+\gamma^{2}\right) \sigma_{\varepsilon}^{2}+\left(\eta_{\alpha \beta \gamma} \sigma_{\Delta I_{1}}\right)^{2}}
\end{aligned}
$$

When the combined cycle slip estimation value is greater than four times the STD, namely $\left|\Delta N_{\alpha \beta \gamma}\right| \geq 4 \cdot \sigma_{\Delta N_{\alpha \beta \gamma}}$, it is considered that cycle slip occurring in this epoch. The corresponding success rate of cycle slip detection can be expressed as:

$$
P=\int_{-4 \sigma_{\Delta N_{\alpha \beta \gamma}}}^{4 \sigma_{\Delta N_{\alpha \beta \gamma}}} \frac{1}{\sqrt{2 \pi} \cdot \sigma_{\Delta N_{\alpha \beta \gamma}}} \exp \left(-\frac{\left(x-\sigma_{\Delta N_{\alpha \beta \gamma}}\right)^{2}}{2 \sigma_{\Delta N_{\alpha \beta \gamma}}^{2}}\right) d x
$$

This paper uses the Maximum Threshold of Ionospheric Variation (MTIV), (Yao et al., 2020) which demonstrates the four times STD of the residual ionosphere to evaluate the performance on the GF-phase combination detecting the insensitive cycle slip group $\Delta N_{1}=\Delta N_{2}=\Delta N_{3}$ and analyze the detection effect of different GF-phase combinations. Table 3 displays the relevant parameters of the BDS-3 GF-phase combination within \pm 5 cycles, and Figure 3 shows the MTIV value of the corresponding GF-phase combination within \pm 100 cycles. As given in Table 3 and Figure 3, MTIV has an extreme value of $0.0744 \mathrm{~m}$, indicating that all GF-phase combinations will lose effective detection for the insensitive cycle slip group $\Delta N_{1}=\Delta N_{2}=\Delta N_{3}$ when the residual ionospheric variation is large. Therefore, under the premise that the optimal EWL code-phase combination loses the performance of detecting insensitive cycle slip groups, the impact of residual ionospheric variation must be effectively eliminated or reduced. In Table 3, the six GF-phase combinations lose the ability to detect insensitive cycle slip combinations under any conditions, so they are not suitable for cycle slip detection. In addition, the MTIV of the GF-phase combination coefficients $(1,-1,0)$, $(1,0,-1)$ and $(2,-1,-1)$ are larger and closer to the extreme value $0.0744 \mathrm{~m}$, and the combined noise is relatively small, more suitable for cycle slip detection. Therefore, they are selected as the optimal GF-phase combination coefficients for $\mathrm{B} 1 \mathrm{I} / \mathrm{B} 3 \mathrm{I} / \mathrm{B} 2 \mathrm{a}$ and B1C/B3I/B2a signals to detect and repair cycle slips.

\subsection{OPTIMAL LINEAR COMBINATIONS BASED ON BDS-3 OBSERVATIONS}

Yao et al. (2020) indicated that the form of two EWL combinations for 2EWL\&1GF does not affect 
Table 3 Optimal GF-phase combination.

\begin{tabular}{cccccccccc}
\hline & \multicolumn{3}{c}{ B1I/B3I/B2a signals } & \multicolumn{5}{c}{ B1C/B3I/B2a signals } \\
\hline$\alpha$ & $\beta$ & $\gamma$ & combined noise $/ \mathrm{m}$ & MTIV/m & $\alpha$ & $\beta$ & $\gamma$ & combined noise /m & MTIV/m \\
\hline 5 & -3 & -2 & 0.018 & 0.0744 & 5 & -3 & -2 & 0.018 & 0.0744 \\
3 & -2 & -1 & 0.011 & 0.0744 & 3 & -2 & -1 & 0.011 & 0.0744 \\
$\mathbf{2}$ & $\mathbf{- 1}$ & $\mathbf{- 1}$ & $\mathbf{0 . 0 0 7}$ & $\mathbf{0 . 0 7 4 3}$ & $\mathbf{2}$ & $\mathbf{- 1}$ & $\mathbf{- 1}$ & $\mathbf{0 . 0 0 7}$ & $\mathbf{0 . 0 7 4 2}$ \\
4 & -3 & -1 & 0.015 & 0.0743 & 5 & -4 & -1 & 0.019 & 0.0741 \\
3 & -1 & -2 & 0.011 & 0.0740 & 5 & -2 & -3 & 0.019 & 0.0740 \\
4 & -1 & -3 & 0.016 & 0.0737 & 3 & -1 & -2 & 0.011 & 0.0738 \\
$\mathbf{1}$ & $\mathbf{- 1}$ & $\mathbf{0}$ & $\mathbf{0 . 0 0 4}$ & $\mathbf{0 . 0 7 3 0}$ & 4 & -1 & -3 & 0.016 & 0.0735 \\
$\mathbf{1}$ & $\mathbf{0}$ & $\mathbf{- 1}$ & $\mathbf{0 . 0 0 5}$ & $\mathbf{0 . 0 7 2 8}$ & 5 & -1 & -4 & 0.020 & 0.0734 \\
4 & 1 & -5 & 0.021 & 0.0716 & $\mathbf{1}$ & $\mathbf{- 1}$ & $\mathbf{0}$ & $\mathbf{0 . 0 0 4}$ & $\mathbf{0 . 0 7 3 2}$ \\
3 & 1 & -4 & 0.017 & 0.0712 & $\mathbf{1}$ & $\mathbf{0}$ & $\mathbf{- 1}$ & $\mathbf{0 . 0 0 4}$ & $\mathbf{0 . 0 7 2 6}$ \\
2 & 1 & -3 & 0.013 & 0.0703 & 2 & 1 & -3 & 0.013 & 0.0702 \\
1 & 1 & -2 & 0.008 & 0.0677 & 1 & 1 & -2 & 0.008 & 0.0676 \\
1 & 2 & -3 & 0.013 & 0.0625 & 1 & 2 & -3 & 0.013 & 0.0626 \\
1 & 3 & -4 & 0.018 & 0.0580 & 2 & -3 & 1 & 0.012 & 0.0624 \\
2 & -5 & 3 & 0.021 & Fail & 2 & -5 & 3 & 0.021 & Fail \\
1 & -5 & 4 & 0.022 & Fail & 1 & -5 & 4 & 0.022 & Fail \\
1 & -4 & 3 & 0.017 & Fail & 1 & -4 & 3 & 0.017 & Fail \\
1 & -3 & 2 & 0.013 & Fail & 1 & -3 & 2 & 0.013 & Fail \\
1 & -2 & 1 & 0.008 & Fail & 1 & -2 & 1 & 0.008 & Fail \\
0 & -1 & 1 & 0.005 & Fail & 0 & -1 & 1 & 0.005 & Fail \\
\hline
\end{tabular}

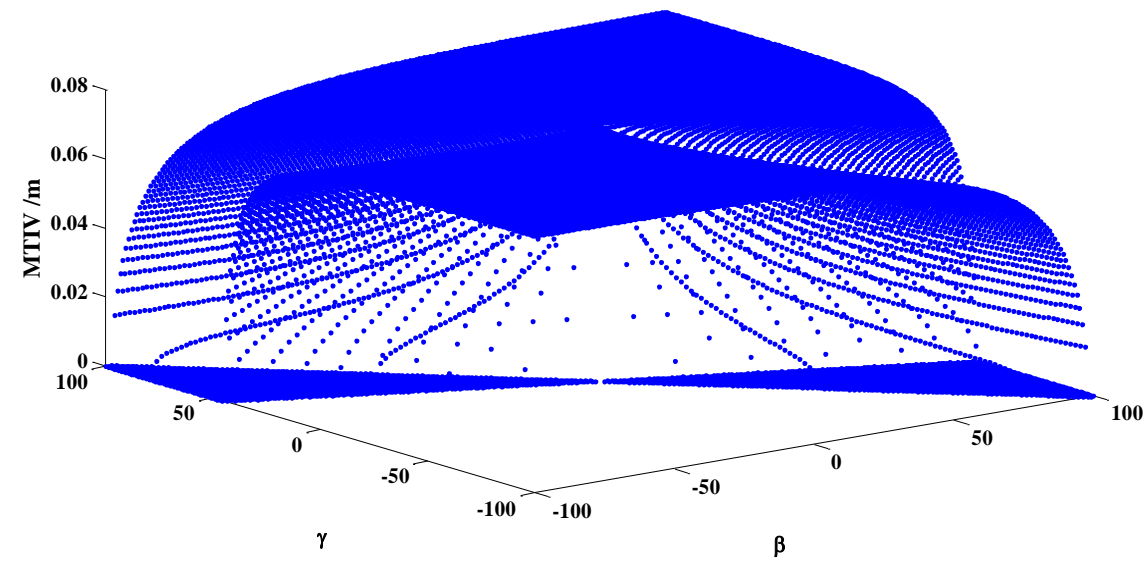

Fig. 3 The MTIV value of GF-phase combinations within \pm 100 cycles.

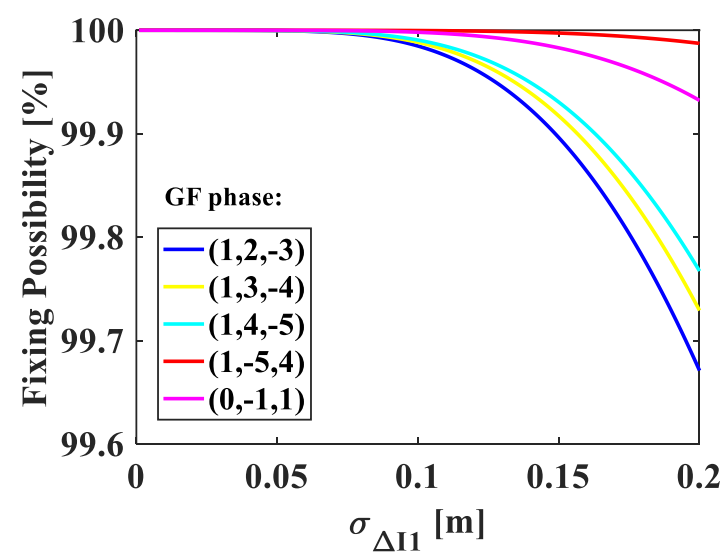

(a) B1I/B3I/B2a signals

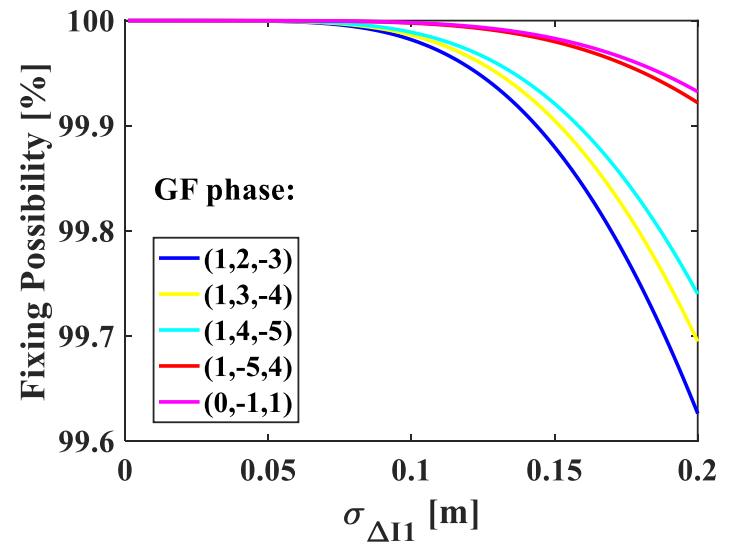

(b) B1C/B3I/B2a signals

Fig. 4 Cycle slip repair success rate for 2EWL\&1GF-phase combination based on BDS-3. 
Table 4 The employed combinations to detect and repair cycle slip for BDS-3 signal.

\begin{tabular}{lccc}
\hline \multirow{2}{*}{ Signal } & EWL code-phase combinations & \multicolumn{2}{c}{ GF-phase combinations } \\
\cline { 3 - 4 } & for detect and repair & detection & repair \\
\hline B1I/B3I/B2a & $(1,-4,3)$ & $(2,-1,-1)$ & $(0,-1,1)$ \\
B1C/B3I/B2a & and $(0,1,-1)$ & or $(1,-1,0)$ & $(2,-1,-1)$ \\
B1C/B1I/B3I/B2a & Based on B1I/B3I/B2a, add extra EWL & $(0,-1,1)$ \\
\hline
\end{tabular}

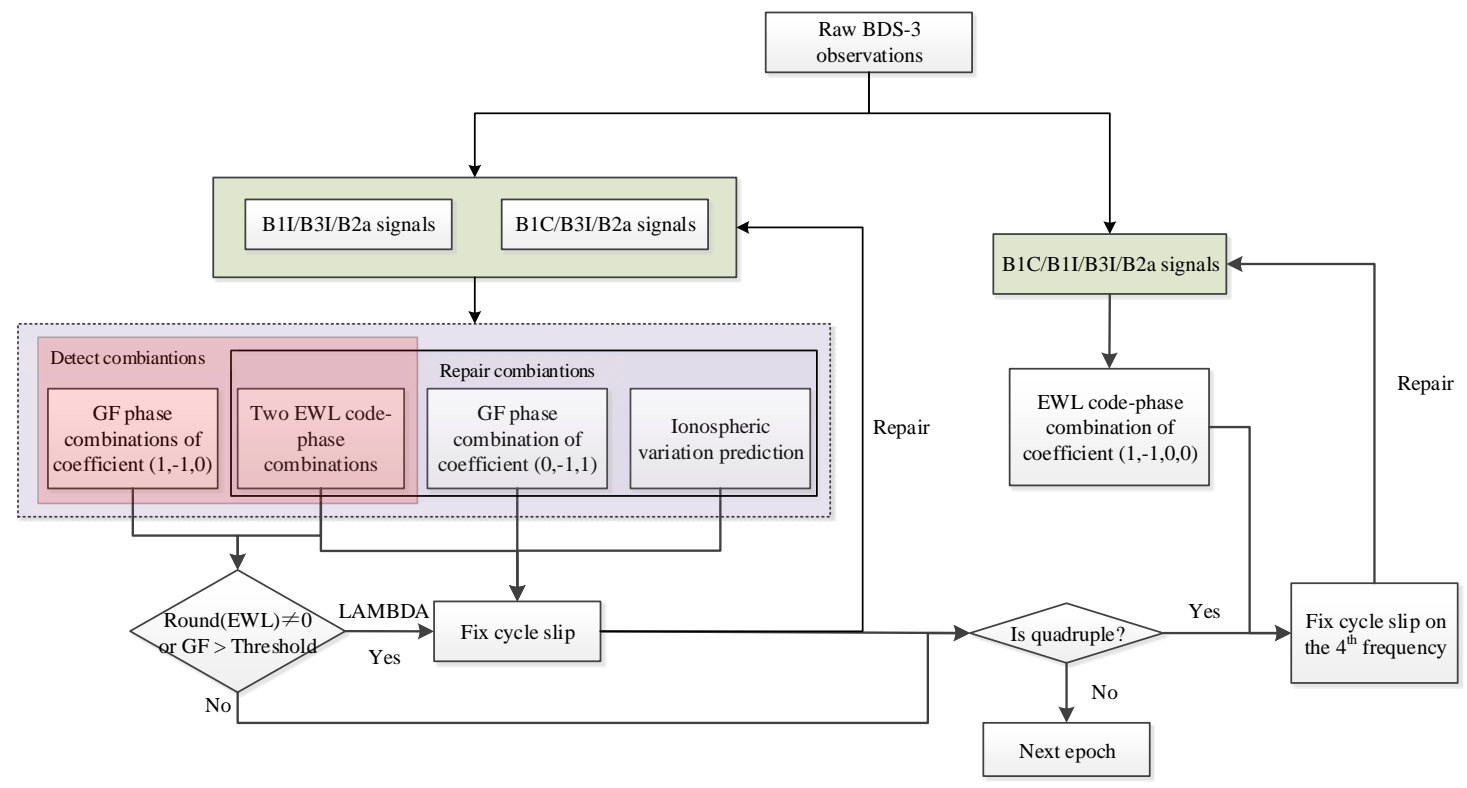

Fig. 5 Process of cycle slip detection and repair for BDS-3 observations.

the success rate of cycle slip repair. Figure 4 reveals the theoretical cycle slip repair success rate of the five optimal 2EWL\&1GF combinations of BDS-3 under the different STD of ionospheric variation. For $\mathrm{B} 1 \mathrm{I} / \mathrm{B} 3 \mathrm{I} / \mathrm{B} 2 \mathrm{a}$ signals and $\mathrm{B} 1 \mathrm{C} / \mathrm{B} 3 \mathrm{I} / \mathrm{B} 2 \mathrm{a}$ signals, the $(1,-5,4)$ and $(0,-1,1)$ combinations have the highest success rate that exceeding $99.99 \%$ even under active ionospheric conditions. Other GF-phase combinations can achieve a high cycle slip repair success rate under stable ionospheric conditions, but the success rate is greatly reduced when the ionosphere is active. Therefore, $(0,-1,1)$ is selected as the optimal combination for cycle slip repair by comprehensive consideration.

At present, the BDS-3 signals received by the receiver are mainly triple-frequency and quad-frequency observation, so we adopt combination observations proposed in Table 4 based on the above analysis of the combined performance of EWL code-phase and GF-phase. Specifically, for triplefrequency signals, to ensure that the employed combinations are linearly independent, two EWL combinations and one GF-phase combination with a large MTIV value are applied, while the cycle slip repair uses the same two EWL combinations and another GF-phase combination. For the quad-frequency signals, it is only necessary to integrate the third EWL combination based on triple- frequency observations to fix the cycle slip value of the fourth frequency.

The classic LAMBDA method is used to fix the cycle slip estimated value, and the reliability of the fixed cycle slip is judged by the Ratio test value. The corresponding covariance matrix of the cycle slip estimated value can be expressed as below (Yao et al., 2020):

$Q_{\Delta N}=\left(A^{T} \cdot Q_{\Delta L}^{-1} \cdot A\right)^{-1}$

Where $A$ is the coefficient matrix, $A_{3 \times 3}=\left[\begin{array}{ccc}i_{1} & j_{1} & k_{1} \\ i_{2} & j_{2} & k_{2} \\ \alpha_{1} \lambda_{1} & \beta_{1} \lambda_{2} & \gamma_{1} \lambda_{3}\end{array}\right] ; Q_{\Delta L}$ denotes the covariance matrix of the three combined observations.

Based on Equation (10), we can know $Q_{\Delta N}$ is not a diagonal matrix. The LAMBDA method can fix the cycle slip reliably through searching and matching the float solution, and direct rounding may not be the optimal value, especially when the ionosphere is active.

Figure 5 is the flow chart of the BDS-3 real-time cycle slip detection and repair method proposed in this paper. With regards to the BDS-3 triple-frequency signal, the GF-phase combination used for cycle slip detection and repair needs to be processed separately, 
Table 5 Data description for the three MGEX MGEX stations.

\begin{tabular}{llrrrl}
\hline Station & County & Latitude & Longitude & Receiver model & Antenna model \\
\hline WUH2 & China & 30.532 & 114.357 & JAVAD TRE_3 & JAVRINGANT_G5T \\
SGOC & Sri Lanka & 6.892 & 79.874 & JAVAD TRE_3 & JAVRINGANT_G5T \\
SUTM & South Africa & -32.381 & 20.811 & JAVAD TRE_3 & JAVRINGANT_G5T \\
\hline
\end{tabular}

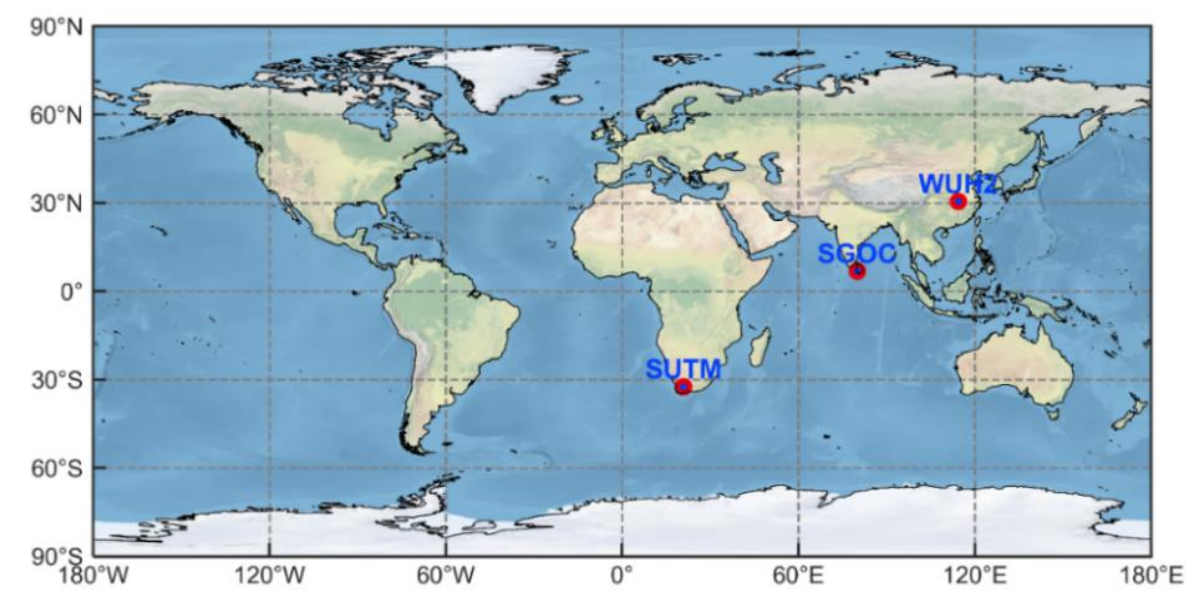

Fig. 6 Location distribution map for the three MGEX stations.

and the observations of the previous epoch without cycle slip must be applied to predict the ionospheric variation in real time and update the GF-phase combined observation value, improving the success rate of cycle slip detection and the accuracy of repair. If the EWL code-phase combinations are not equal to zero or the GF-phase combination is greater than four times the STD, it means that the threshold condition of cycle slip detection in the figure is satisfied. Then, using the classic LAMBDA method fixes the cycle slip estimation value. The Ratio test is employed to evaluate the reliability of the fixed cycle slip estimation value and repair the original phase observations which are applied to update the ionospheric variations. Finally, the satellite signal is checked to see whether it is quad-frequency and if so, we use the additional EWL code-phase combination and the triple-frequency fixed cycle slip value to determine and repair the cycle slip occurring on the fourth frequency signal. Otherwise, the observation data of the next epoch continues to be processed.

This paper studies the different combinations of satellite signals under normal circumstances. The model of cycle slip detection and repair is universal and can be modularized. Similarly, other combined observations of BDS-3 quad-frequency signals can also combine an additional EWL code-phase combination on the basis of the triple-frequency signals which can simplify the process and calculation improving the success rate and reliability of cycle slip detection and repair based on the strategy proposed in this paper.

\section{DATA COLLECTION AND EXPERIMENT ANALYSIS \\ 3.1. TRIPLE-FREQUENCY OBSERVATIONS TEST UNDER THE HIGHLY ACTIVE IONOSPHERIC CONDITION}

To check the effectiveness of the proposed algorithm in this paper, a set of real BDS-3 B1I/B3I/B2a observations under highly active ionospheric conditions are employed. We collected the data from the Multi-GNSS Experiment (MGEX) of the International GNSS Service (IGS), including the WUH2 station, SGOC station, and SUTM station on May 14, 2019, with the sampling interval of 30s. From Table 5 and Figure 6, we can see the position, receiver model, antenna model and location distribution map of the three MGEX stations. The Kp index can be used to reflect the active conditions of the ionosphere, reaching a maximum of 7 at 7:30 on May 14, 2019, as shown in Figure 7.

Figure 8 shows the real-time detection results of the cycle slips of the $\mathrm{C} 22$ and C29 satellites at the SGOC station. It can be seen that there is no obvious system deviation in the GF-phase combination after the correction of the ionospheric variation, indicating the ionospheric correction model used in this article is reasonable.

The C22 satellite detected a few cycle slips and the ionospheric variation was small. The ionospheric variation of the C29 satellite is relatively large, and no cycle slip has been detected except for the 870th epoch position (the satellite elevation angle at this epoch position is less than 10 degree). Besides, Figure 9 and Figure 10 show the real-time cycle slip detection 


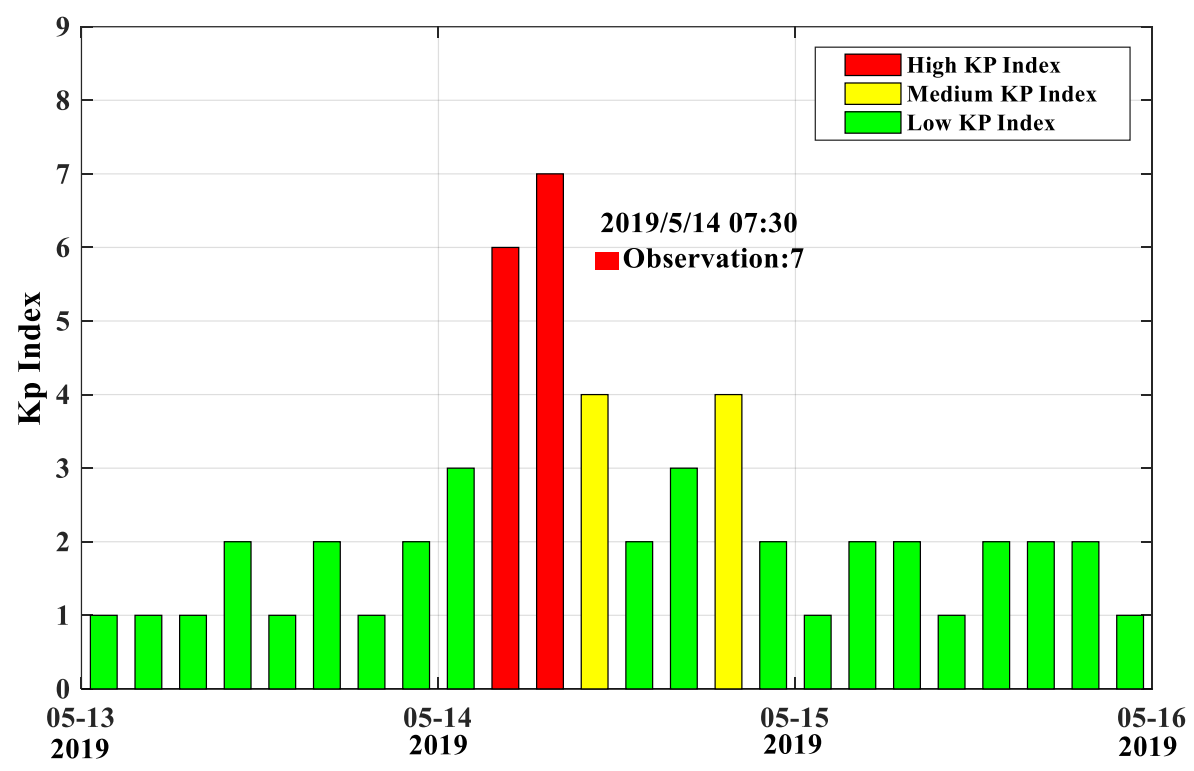

Fig. 7 Kp index on May 14, 2019.

C22

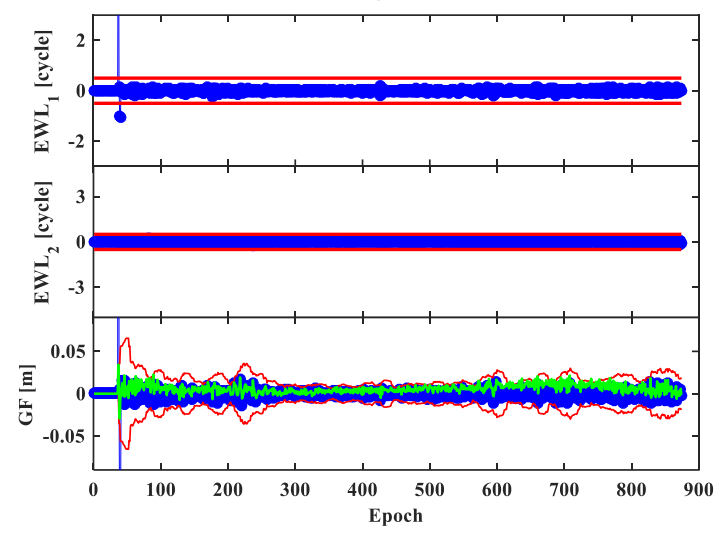

(a) PRN C22
C29

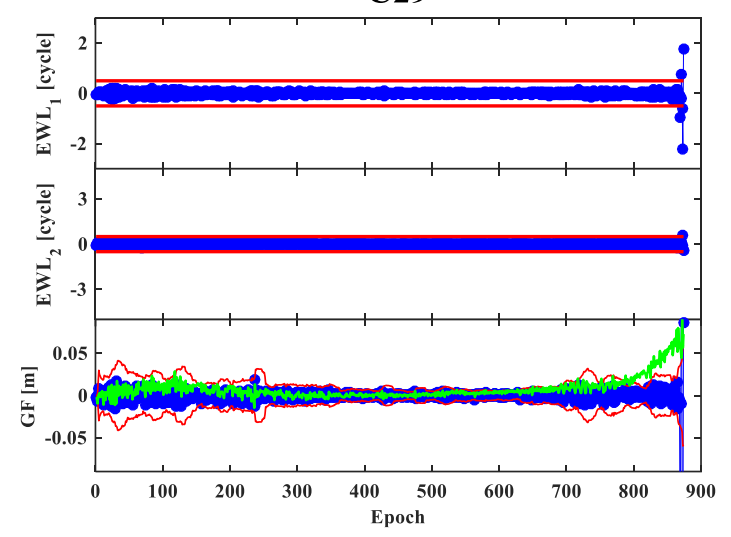

(b) PRN C29

Fig. 8 SGOC station cycle slip real-time detection results (Blue curve denotes detected value; red denotes threshold values; green curve represents the ionospheric variation and the same below).

\section{C21}

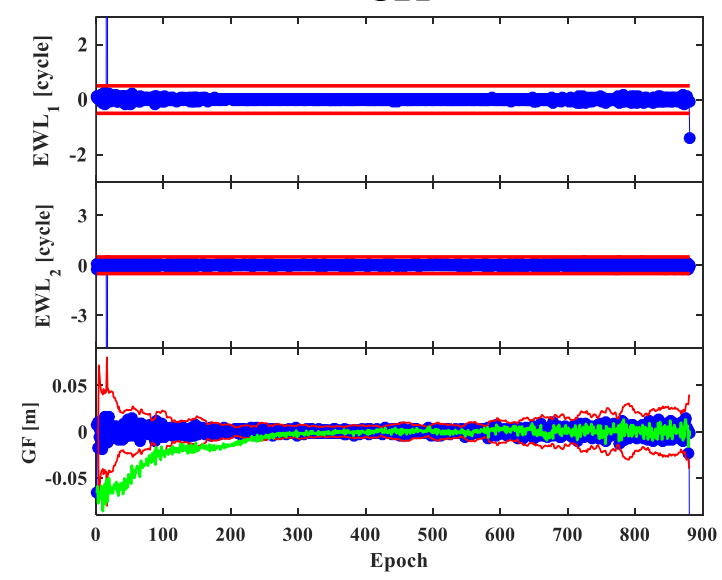

(a) PRN C21

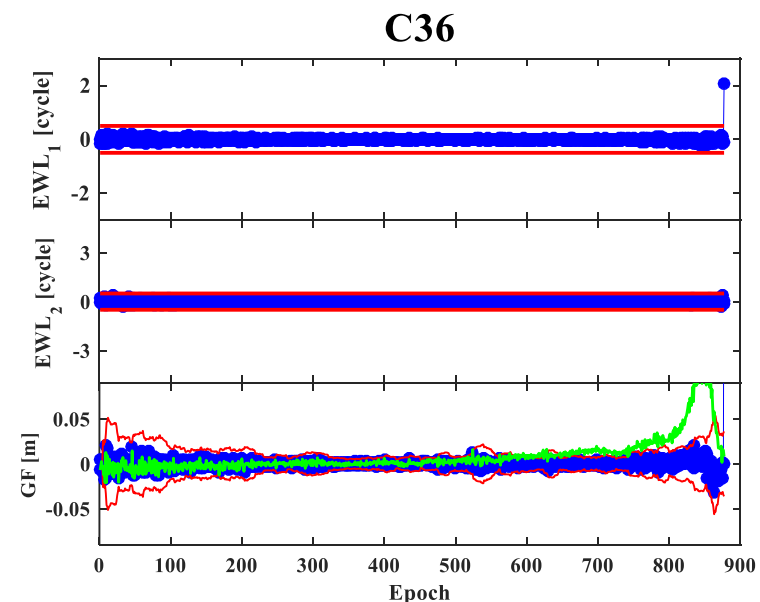

(b) PRN C36

Fig. 9 WUH2 station cycle slip real-time detection results. 
C22

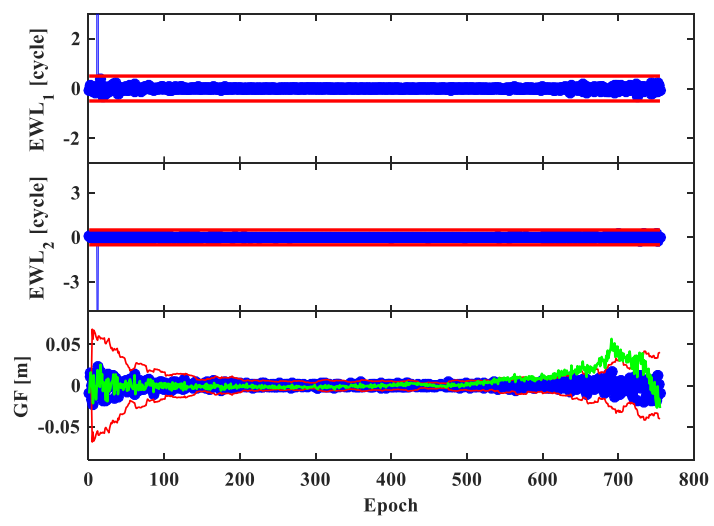

(a) PRN C22.
C27

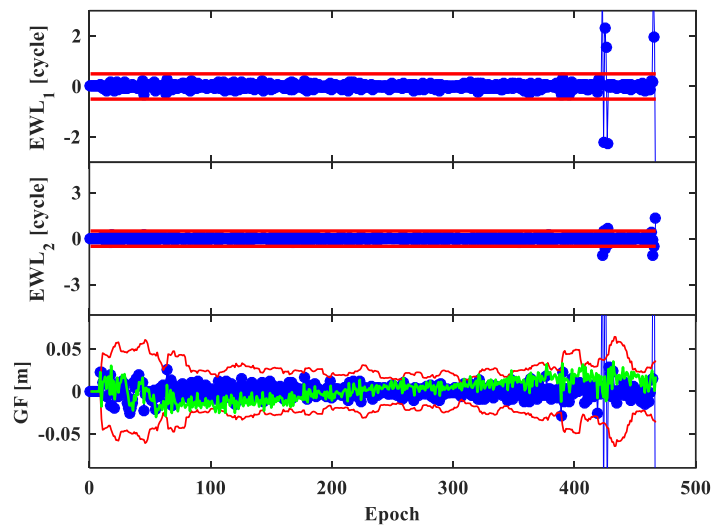

(b) PRN C27.

Fig. 10 SUTM station cycle slip real-time detection results.

Table 6 Simulated cycle slip repair results of the static BDS-3 triple-frequency observations*.

\begin{tabular}{|c|c|c|c|c|c|c|c|c|c|c|c|}
\hline \multirow{2}{*}{ Station } & \multirow{2}{*}{ PRN } & \multirow{2}{*}{ Epoch } & \multirow{2}{*}{$\begin{array}{l}\text { Cycle slip } \\
\text { value }\end{array}$} & \multirow{2}{*}{$\begin{array}{l}\text { Cycle slip } \\
\text { type }\end{array}$} & \multicolumn{3}{|c|}{$\begin{array}{l}\text { Floating solution } \\
\text { of cycle slip }\end{array}$} & \multicolumn{3}{|c|}{$\begin{array}{l}\text { Fixed solution } \\
\text { of cycle slip }\end{array}$} & \multirow{2}{*}{ Ratio } \\
\hline & & & & & $\begin{array}{l}\triangle N_{1} \\
\text { /cycle }\end{array}$ & $\begin{array}{c}\triangle N_{2} \\
\text { /cycle }\end{array}$ & $\begin{array}{c}\triangle N_{3} \\
\text { /cycle }\end{array}$ & $\begin{array}{c}\triangle N_{1} \\
\text { /cycle } \\
\end{array}$ & $\begin{array}{l}\triangle N_{2} \\
\text { /cycle }\end{array}$ & $\begin{array}{l}\triangle N_{3} \\
\text { /cycle }\end{array}$ & \\
\hline \multirow{5}{*}{ WUH2 } & $\mathrm{C} 21$ & 150 & $(1,0,0)$ & $\mathrm{P} \& \mathrm{~S}$ & 1.19 & 0.19 & 0.19 & 1 & 0 & 0 & 45.46 \\
\hline & $\mathrm{C} 21$ & 300 & $(0,1,1)$ & $\mathrm{P} \& \mathrm{~S}$ & 0.01 & 1.01 & 1.01 & 0 & 1 & 1 & 147.90 \\
\hline & $\mathrm{C} 21$ & 450 & $(1,1,1)$ & $\mathrm{P} \& \mathrm{~S}$ & 1.10 & 1.10 & 1.10 & 1 & 1 & 1 & 20.73 \\
\hline & $\mathrm{C} 21$ & 600 & $(100,100,100)$ & $\mathrm{P} \& \mathrm{~L}$ & 100.13 & 100.13 & 100.13 & 100 & 100 & 100 & 59.28 \\
\hline & $\mathrm{C} 21$ & 750 & $(99,100,101)$ & L\&A & 98.71 & 99.71 & 100.71 & 99 & 100 & 101 & 20.83 \\
\hline \multirow{5}{*}{ SGOC } & $\mathrm{C} 29$ & 150 & $(1,0,0)$ & $P \& S$ & 1.37 & 0.37 & 0.37 & 1 & 0 & 0 & 18.02 \\
\hline & $\mathrm{C} 29$ & 300 & $(0,1,1)$ & $\mathrm{P} \& S$ & 0.11 & 1.11 & 1.11 & 0 & 1 & 1 & 15.91 \\
\hline & $\mathrm{C} 29$ & 450 & $(1,1,1)$ & $P \& S$ & 1.13 & 1.13 & 1.13 & 1 & 1 & 1 & 59.33 \\
\hline & $\mathrm{C} 29$ & 600 & $(100,100,100)$ & $\mathrm{P} \& \mathrm{~L}$ & 99.92 & 99.92 & 99.92 & 100 & 100 & 100 & 463.76 \\
\hline & $\mathrm{C} 29$ & 750 & $(99,100,101)$ & L\&A & 99.44 & 100.44 & 101.44 & 99 & 100 & 101 & 5.35 \\
\hline \multirow{5}{*}{ SUTM } & $\mathrm{C} 33$ & 150 & $(1,0,0)$ & $\mathrm{P} \& \mathrm{~S}$ & 1.15 & 0.15 & 0.15 & 1 & 0 & 0 & 112.64 \\
\hline & $\mathrm{C} 33$ & 300 & $(0,1,1)$ & $\mathrm{P} \& S$ & 0.00 & 1.00 & 1.00 & 0 & 1 & 1 & 2085.02 \\
\hline & $\mathrm{C} 33$ & 450 & $(1,1,1)$ & P\&S & 1.00 & 1.00 & 1.00 & 1 & 1 & 1 & 1546.80 \\
\hline & $\mathrm{C} 33$ & 600 & $(100,100,100)$ & $\mathrm{P} \& \mathrm{~L}$ & 100.08 & 100.08 & 100.08 & 100 & 100 & 100 & 347.34 \\
\hline & $\mathrm{C} 33$ & 750 & $(99,100,101)$ & L\&A & 99.01 & 100.01 & 101.01 & 99 & 100 & 101 & 321.74 \\
\hline
\end{tabular}

* In Table, S represents a small cycle slip, L denotes a large cycle slip, and P is a special cycle slip which generally means that the cycle slip cannot be effectively detected by cycle slip estimation value including the insensitive cycle slip groups. Moreover, A represents a similar cycle slip. And the statement in the following tables are consistent with these.

effects of $\mathrm{C} 21, \mathrm{C} 36, \mathrm{C} 22$, and $\mathrm{C} 27$ satellites at WUH2 and SUTM stations, respectively, and the results are the same as those at SGOC station.

In order to intuitively demonstrate the performance of the cycle slip repair model, this paper adds different types of cycle slip groups to the original phase observations of different stations, different satellites, and different epochs, including big cycle slip groups, small cycle slip groups, and special cycle slip groups including insensitive cycle slip groups and similar cycle slip groups. According to (Yao et al., 2019), we can know that the ratio value is mainly related to the ionospheric delay, the success rate of cycle slip repair, and the selected cycle slip repair model. Theoretically, the F-ratio threshold value is different for each epoch, however the error in the residual ionosphere is smoothed within a period, an approximate value can be set. After testing, under the condition that the GF combination is $(0,-1,1)$, the ionospheric delay is $7 \mathrm{~mm}$, and the cycle slip repair rate is $99.999 \%$, which are similar to the cycle slip repair model in (Yao et al., 2019), so the Ratio value in this paper is set to 3 conservatively.

Table 6 indicates the results of cycle slip repair, and the cycle slip detection effect is shown in Figure 11. It can be clearly seen from Table 6 that all cycle slips have been correctly repaired. At the $750^{\text {th }}$ epoch, the Ratio test value of the C29 satellite on the SGOC station is relatively small reaching 5.35 indicating that the fixed cycle slip value is not very reliable, but it is still fixed correctly. Besides, it can be found that the float solution of the cycle slip of the epoch is closer to 0.5 cycle, which explains the reason for the poor reliability of the cycle slip fixed value. Figure 11 demonstrates that the EWL $\mathrm{EL}_{1}$ combination and GFphase combination can effectively detect all cycle slip 


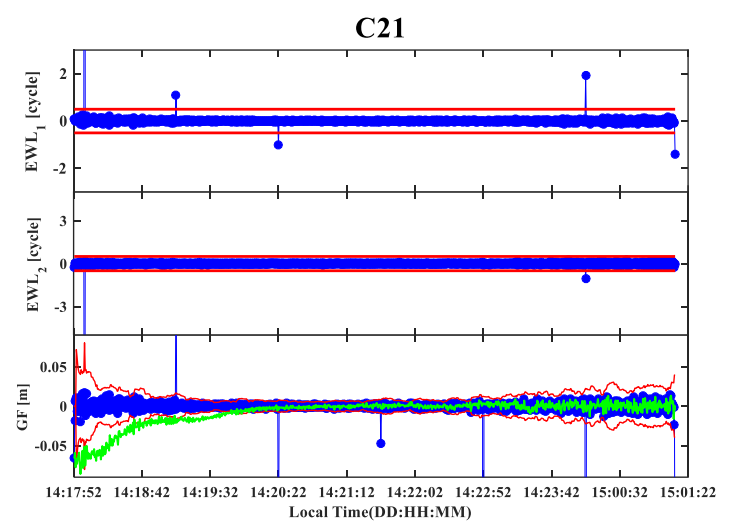

(a) WUH2 station

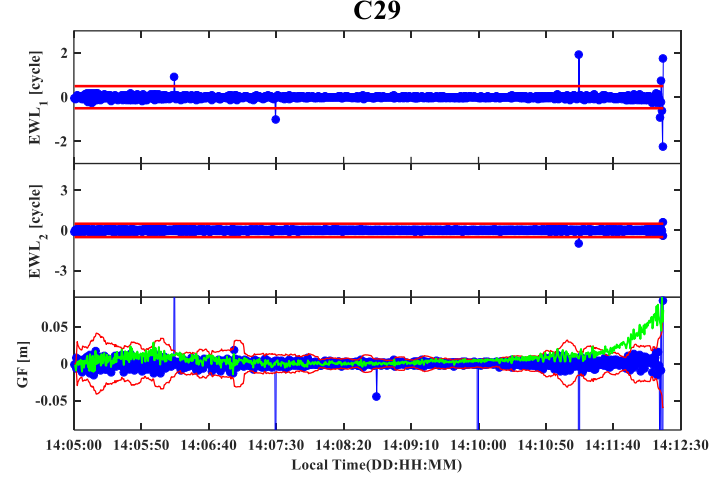

(b) SGOC station.

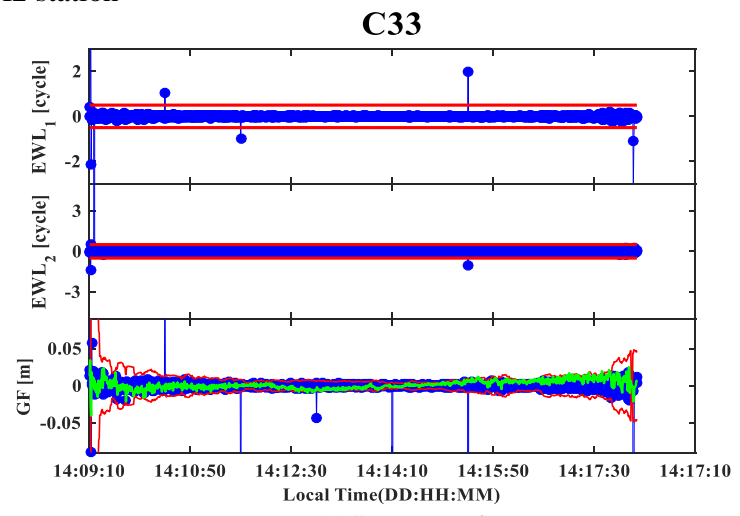

(c)SUTMstation.

Fig. 11 Real-time detection results of simulated cycle slips for static BDS-3 triple-frequency observations with the sampling interval of 30 s under the active ionospheric conditions.

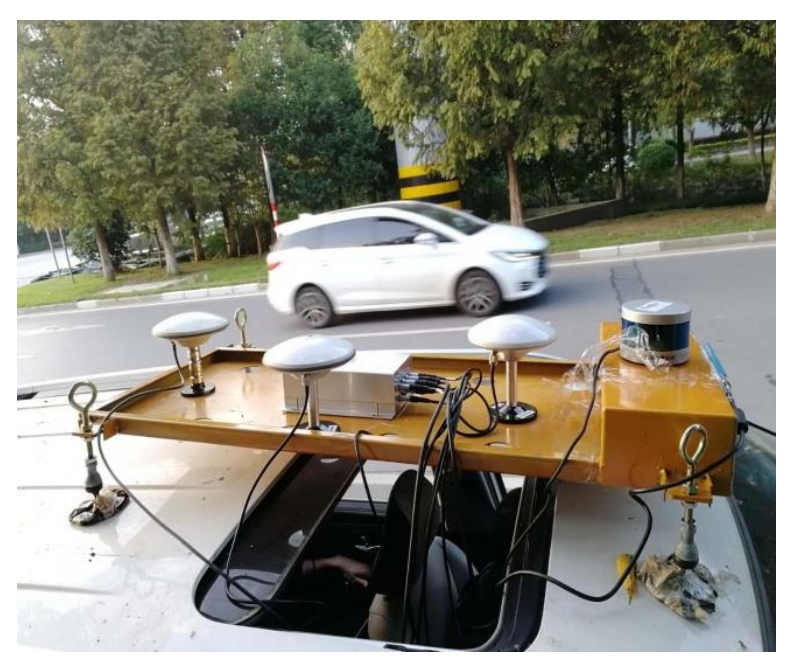

(a) Measurement vehicle.

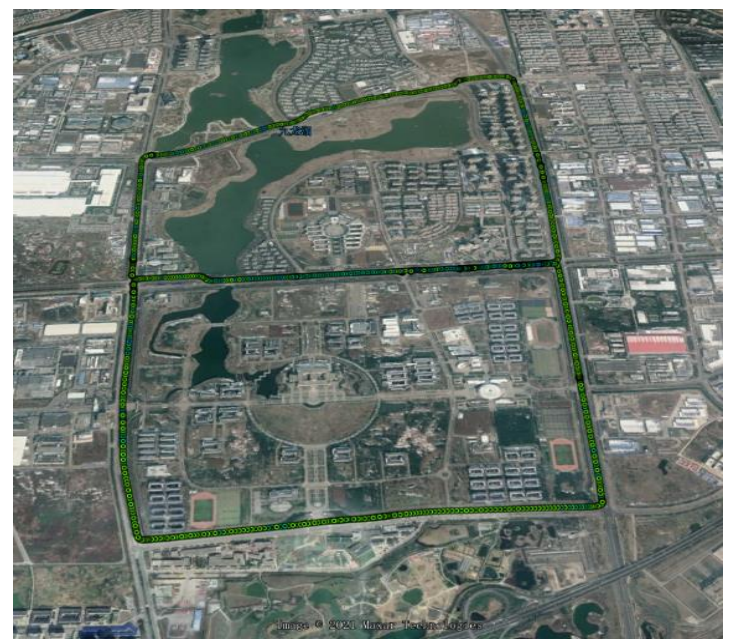

(b) Trajectory of the car.

Fig. 12 Measurement vehicle for testing in the dynamic experiment (the trajectory of the car with a green line).

groups except the insensitive cycle slip groups, and the $\mathrm{EWL}_{2}$ combination can availably detect all the cycle slip groups except the equivalent cycle slip groups on the second and third frequency. In summary, although the three combinations have certain disadvantages, using them in combination can effectively detect all cycle slip groups and ensure that the cycle slips are correctly repaired.

\subsection{DYNAMIC TRIPLE-FREQUENCY OBSERVATIONS TEST}

In this section, dynamic BDS-3 triple-frequency observations on $\mathrm{B} 1 \mathrm{C} / \mathrm{B} 3 \mathrm{I} / \mathrm{B} 2 \mathrm{a}$ signals with the sampling interval of $1 \mathrm{~s}$ were collected to verify the performance of the proposed algorithm in Nanjing on October 22, 2020. A GNSS receiver K708 manufactured by ComNav Technology Ltd. in Shanghai was used to construct the dynamic testing 
C22

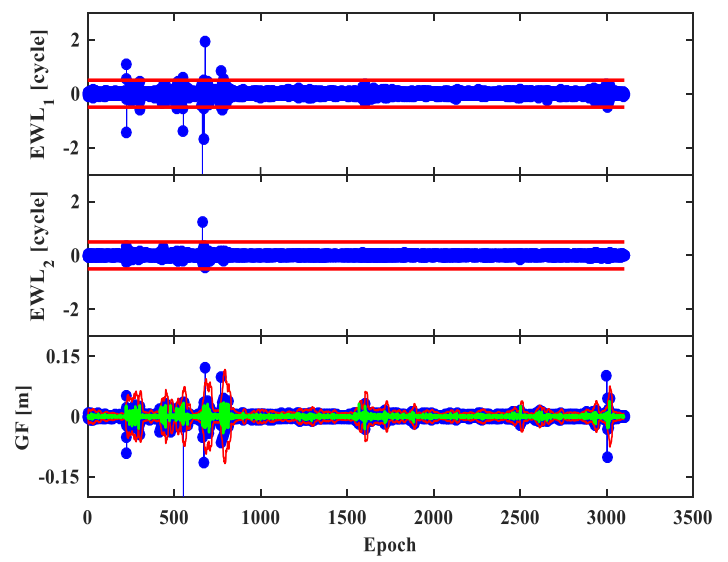

(a) PRN C22.

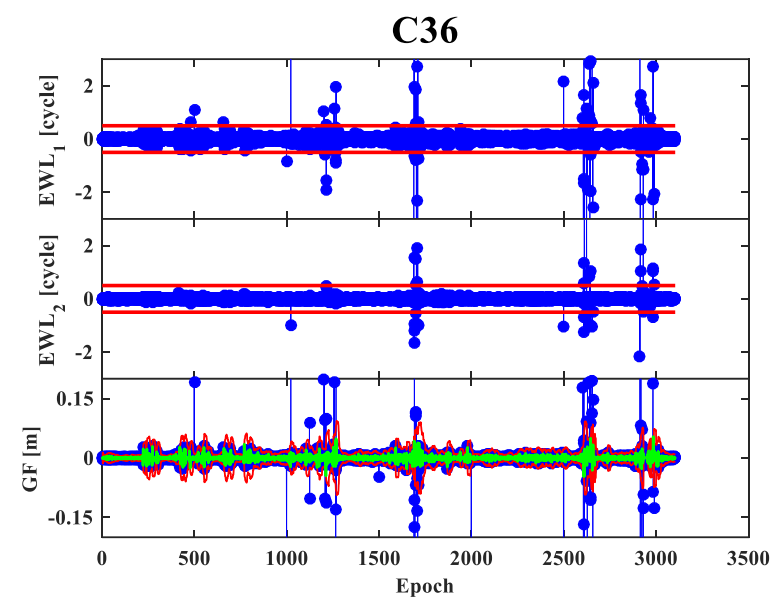

(b) PRN C36.

Fig. 13 Real-time detection results of real cycle slips of static BDS-3 triple-frequency observations with the sampling interval of $1 \mathrm{~s}$.

Table 7 Simulated cycle slip repair results of the BDS-3 dynamic triple-frequency observations.

\begin{tabular}{|c|c|c|c|c|c|c|c|c|c|c|}
\hline \multirow{2}{*}{ PRN } & \multirow{2}{*}{ Epoch } & \multirow{2}{*}{$\begin{array}{l}\text { Cycle slip } \\
\text { value }\end{array}$} & \multirow{2}{*}{$\begin{array}{l}\text { Cycle slip } \\
\text { type }\end{array}$} & \multicolumn{3}{|c|}{$\begin{array}{l}\text { Floating solution } \\
\text { of cycle slip }\end{array}$} & \multicolumn{3}{|c|}{$\begin{array}{l}\text { Fixed solution } \\
\text { of cycle slip }\end{array}$} & \multirow{2}{*}{ Ratio } \\
\hline & & & & $\begin{array}{l}\triangle N_{1} \\
\text { /cycle }\end{array}$ & $\begin{array}{c}\triangle N_{2} \\
\text { /cycle }\end{array}$ & $\begin{array}{l}\triangle N_{3} \\
\text { /cycle }\end{array}$ & $\begin{array}{l}\triangle N_{1} \\
\text { /cycle }\end{array}$ & $\begin{array}{l}\triangle N_{2} \\
\text { /cycle }\end{array}$ & $\begin{array}{c}\triangle N_{3} \\
\text { /cycle }\end{array}$ & \\
\hline \multirow{5}{*}{$\mathrm{C} 22$} & 500 & $(1,0,0)$ & $\mathrm{P} \& \mathrm{~S}$ & 1.53 & 0.53 & 0.53 & 1 & 0 & 0 & 11.99 \\
\hline & 1000 & $(0,1,1)$ & $\mathrm{P} \& \mathrm{~S}$ & 0.18 & 0.82 & 0.82 & 0 & 1 & 1 & 172.85 \\
\hline & 1500 & $(1,1,1)$ & $\mathrm{P} \& S$ & 0.96 & 0.96 & 0.96 & 1 & 1 & 1 & 119.73 \\
\hline & 2000 & $(100,100,100)$ & P\&L & 100.03 & 100.03 & 100.03 & 100 & 100 & 100 & 199.33 \\
\hline & 2500 & $(99,100,101)$ & L\&A & 98.58 & 99.58 & 100.58 & 99 & 100 & 101 & 32.58 \\
\hline
\end{tabular}

experiment. Figure 12 shows the dynamic data acquisition equipment and the trajectory of the car.

For the B1C/B3I/B2a signals, we use the corresponding combination observations selected in Table 4 to detect and repair cycle slip. Taking nearly $1 \mathrm{~h}$ of BDS-3 data from the $\mathrm{C} 22$ and $\mathrm{C} 36$ satellite as an example, the cycle slip detection values of EWL1, EWL2, and GF combinations along with the corresponding thresholds and ionospheric variation were drawn in Figure 13.

As shown in Figure 13, due to the interference of trees and buildings, the quality of the dynamic data is much worse than that of the static data. There are 51 cycle slips happened on the observation data with total 3104 epochs. The 2EWL\&1GF combination can effectively detect all cycle slips including insensitive cycle slips. For example, at the 3025th epoch, the two EWL combinations cannot detect the cycle slip occurring on the C22 satellite data, but the GF combination can be successfully detected.

To verify the effectiveness of the cycle slip repair algorithm proposed in this paper, different types of cycle slip groups are artificially added to the C22 satellite original phase observation of different satellites on different epochs. Table 7 lists the simulation cycle slip repair results, such as the fixed solution of cycle slip and the corresponding Ratio test value of the fixed solution for the cycle slips. The cycle slip detection results are shown in Figure 14.
From Table 7, we know that all cycle slips that have been added can be correctly repaired, and the corresponding Ratio values are all large, indicating that the cycle slip repair results are reliable. At the 500th epoch, the float solution of the cycle slip value exceeds 0.5 cycle, but it can still be successfully repaired proving the applicability of the algorithm. Figure 14 shows the result of cycle slip detection results for the C22 satellite using the 2EWL\&1GF combination. From Figure 14, we can know all the cycle slips are successfully detected and repaired, and the same conclusion can be drawn as the above static triple-frequency experiment.

\subsection{STATIC QUAD-FREQUENCY OBSERVATIONS TEST}

The static BDS-3 quad-frequency observations on $\mathrm{B} 1 \mathrm{C} / \mathrm{B} 1 \mathrm{I} / \mathrm{B} 3 \mathrm{I} / \mathrm{B} 2 \mathrm{a}$ signals with the sampling interval of 1s were collected on November 6, 2020. The model of the GNSS receiver is Trimble BD970 produced by Trimble Navigation, Ltd. in America.

To illustrate the application effect of the algorithm proposed in this paper for BDS-3 quadfrequency observations, the cycle slip groups are artificially added to the original carrier observations of the C21 satellite. The cycle slip repair results with related parameters are listed in Table 8. 
C22

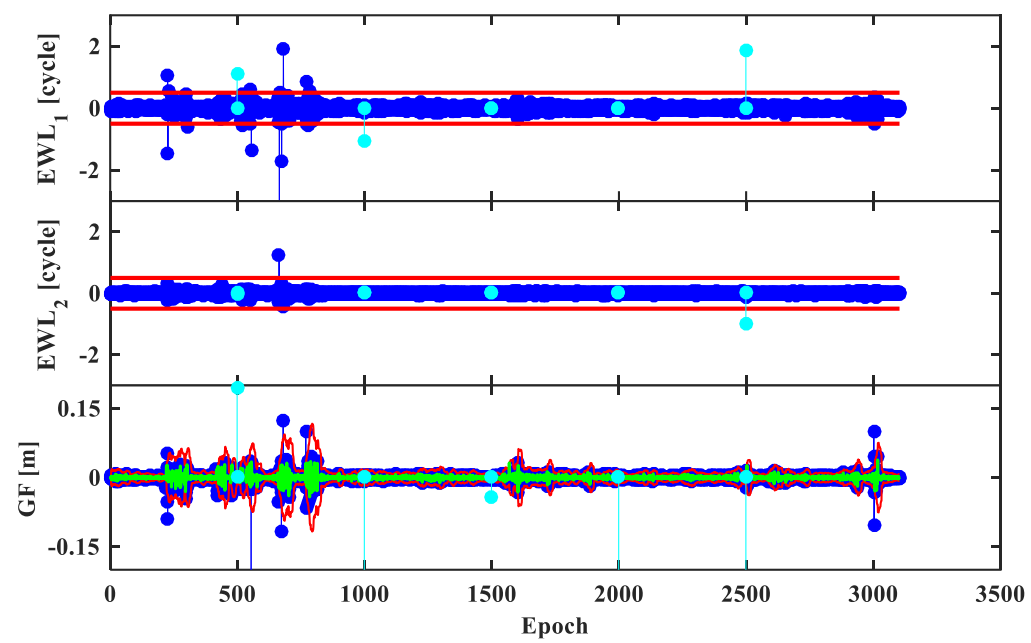

Fig. 14 Real-time detection results of simulated cycle slips of BDS-3 dynamic triple-frequency observations with the sampling interval of $1 \mathrm{~s}$.

(The cyan curve represents the value of the added simulated cycle slip in Table 7).

Table 8 Simulated cycle slip repair results of the static BDS-3 quad-frequency observations.

\begin{tabular}{|c|c|c|c|c|c|c|c|}
\hline \multirow[b]{2}{*}{ Epoch } & \multirow[b]{2}{*}{$\begin{array}{l}\text { Cycle slip } \\
\text { value }\end{array}$} & \multirow[b]{2}{*}{$\begin{array}{c}\text { Cycle slip } \\
\text { type }\end{array}$} & \multicolumn{4}{|c|}{ Fixed solution of cycle slip } & \multirow[b]{2}{*}{ Ratio } \\
\hline & & & $\begin{array}{c}\triangle N_{1} \\
\text { /cycle }\end{array}$ & $\begin{array}{c}\triangle N_{2} \\
\text { /cycle }\end{array}$ & $\begin{array}{c}\triangle N_{3} \\
\text { /cycle }\end{array}$ & $\begin{array}{c}\triangle N_{4} \\
\text { /cycle }\end{array}$ & \\
\hline 400 & $(0,1,0,0)$ & $P \& S$ & 0 & 1 & 0 & 0 & 1874.78 \\
\hline 800 & $(1,0,0,0)$ & $P \& S$ & 1 & 0 & 0 & 0 & 320.14 \\
\hline 1200 & $(0,0,1,1)$ & $P \& S$ & 0 & 0 & 1 & 1 & 853.59 \\
\hline 1600 & $(0,1,1,1)$ & $P \& S$ & 0 & 1 & 1 & 1 & 422.61 \\
\hline 2000 & $(1,1,1,1)$ & $P \& S$ & 1 & 1 & 1 & 1 & 548.35 \\
\hline 2400 & $(0,100,0,0)$ & $\mathrm{L}$ & 0 & 100 & 0 & 0 & 230.02 \\
\hline 2800 & $(100,0,0,0)$ & $\mathrm{L}$ & 100 & 0 & 0 & 0 & 1205.56 \\
\hline 3200 & $(0,100,100,100)$ & $\mathrm{P} \& \mathrm{~L}$ & 0 & 100 & 100 & 100 & 3718.18 \\
\hline 3600 & $(100,100,100,100)$ & $P \& L$ & 100 & 100 & 100 & 100 & 771.62 \\
\hline 4000 & $(0,99,100,101)$ & L\&A & 0 & 99 & 100 & 101 & 326.46 \\
\hline 4400 & $(100,99,100,101)$ & L\&A & 100 & 99 & 100 & 101 & 3717.62 \\
\hline
\end{tabular}

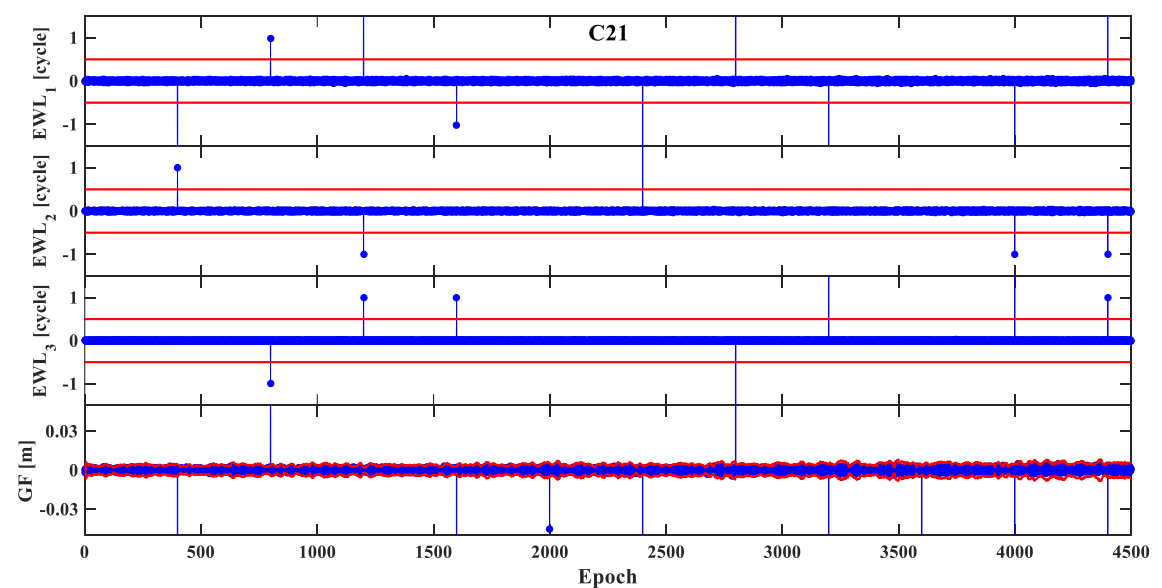

Fig. 15 Real-time detection results of simulated cycle slips of static BDS-3 quad-frequency observations with the sampling interval of $1 \mathrm{~s}$. 
It can be evidently known from Table 7 that the cycle slips artificially added are all correctly repaired, and the corresponding Ratio test values are all large, indicating that the results of cycle slip repair are reliable. Figure 15 shows the result of using the three EWL code-phase combinations and one GF-phase combination to detect cycle slip. In addition, the additional $\mathrm{EWL}_{3}$ combination can detect cycle slip groups except for B1C/B1I equivalent cycle slip, and the detection accuracy is very high. And the same conclusion can be drawn as the above triple-frequency experiments.

\section{CONCLUSION}

In this paper, the combination of EWL codephase and GF-phase is used to detect and repair cycle slips in real time for BDS-3 B1I/B3I/B2a and B1C/B1I/B3I/B2a phase observations.Meanwhile, we employ the classic LAMBDA method and Ratio test to fix the cycle slip estimation value and evaluate the reliability separately. The EWL code-phase-IF combination should not be used in order to minimize the influence on the combined noise of code-phase combination and increase the rounding success rate. Theoretically, the cycle slip repair success rate of the GF-phase combination $(1,-5,4)$ is the highest and the cycle slip repair success rate is greater than $99.99 \%$, even under active ionospheric conditions. Besides, the cycle slip repair success rate with the coefficient of $(0,-1,1)$ is also close to $99.99 \%$.

It is necessary to use the ionospheric prediction model to correct the ionospheric deviation of the GFphase combination. Otherwise, it will greatly reduce the total success rate of cycle slip repair."

BDS-3 triple-frequency and quad-frequency data are used to verify the effectiveness of this algorithm under different observation conditions i.e highly active ionospheric conditions and low sampling rate. Both real and simulated cycle slip test results show that the method proposed in this paper can detect all cycle slip groups effectively and repair them correctly, especially for small cycle slips and insensitive cycle slips.

It should be noted that our proposed method can also be used in the other GNSS to detect and repair cycle slips occurring on triple-frequency and quadfrequency signals effectively, that is, the model of cycle slip detection and repair is universal and can be modularized.

\section{ACKNOWLEDGMENT}

IGS MGEX is gratefully acknowledged for providing BDS-3 data. We express our sincere gratitude to anonymous reviewers for helpful suggestions. This work is partially supported by the National Natural Science Foundation of China (Grant No. 41774027) and the National Key Technologies R\&D Program (Grant No. 2016YFB0502101).

\section{REFERENCES}

Bisnath, S.B.: 2000, Efficient, automated cycle-slip correction of dual-frequency kinematic GPS data. Proc. 13th International Technical Meeting of the Satellite Division of the Institute of Navigation (ION GPS 2000), Salt Lake City, 145-154.

Blewitt, G.: 1990. An automatic editing algorithm for GPS data. Geophys. Res. Lett., 17, 3, 199-202. DOI: 10.1029/GL017i003p00199

Cai, C., Liu, Z., Xia, P. and Dai, W.: 2013, Cycle slip detection and repair for undifferenced GPS observations under high ionospheric activity. GPS Solut., 17, 2, 247-260. DOI: $10.1007 / \mathrm{s} 10291-012-0275-7$

Chang, G., Xu, T., Yao, Y. and Wang, Q.: 2018, Adaptive Kalman filter based on variance component estimation for the prediction of ionospheric delay in aiding the cycle slip repair of GNSS triple-frequency signals. J. Geod., 92, 11, 1241-1253. DOI: $10.1007 / \mathrm{s} 00190-018-1116-4$

Deng, C., Cui, J., Tang, W., Zou, X. and Shu, L.: 2019, Reliable real-time triple-frequency cycle slip detection and recovery with adaptive detection thresholds. Meas. Sci. Technol., 30, 5, 055007.

DOI: 10.1088/1361-6501/ab0357

Fan, X., Tian, R., Dong, X., Shuai, W. and Fan, Y.: 2020, Cycle slip detection and repair for BeiDou-3 triplefrequency signals. Int. J. Adv. Robot. Syst., 17, 3, 1729881420926404.

DOI: $10.1177 / 1729881420926404$

Hatch, R.: 1983, The synergism of GPS code and carrier measurements. International Geodetic Symposium on Satellite Doppler Positioning, New Mexico, 12131231.

Huang, L., Lu, Z., Zhai, G., Ouyang, Y., Huang, M., Lu, X., ... and $\mathrm{Li}, \mathrm{K} .:$ 2016, A new triple-frequency cycle slip detecting algorithm validated with BDS data. GPS Solut., 20, 4, 761-769.

DOI: $10.1007 / \mathrm{s} 10291-015-0487-8$

Kim, D. and Langley, R.B.: 2001, Instantaneous real-time cycle-slip correction of dual frequency GPS data. Proc. International Symposium on Kinematic Systems in Geodesy, Geomatics and Navigation, Banff, 255264.

Li, B., Qin, Y. and Liu, T.: 2019a, Geometry-based cycle slip and data gap repair for multi-GNSS and multifrequency observations. J. Geod., 93, 3, 399-417. DOI: $10.1007 / \mathrm{s} 00190-018-1168-5$

Li, F., Gao, J., Li, Z., Qian, N., Yang, L. and Yao, Y.: 2019b, A step cycle slip detection and repair method based on double-constraint of ephemeris and smoothed pseudorange. Acta Geodyn. Geomater, 16, 4, 337348. DOI: 10.13168/AGG.2019.0028

Li, J., Yang, Y., He, H. and Guo, H.: 2017, An analytical study on the carrier-phase linear combinations for triple-frequency GNSS. J. Geod., 91, 2, 151-166. DOI: 10.1007/s00190-016-0945-2

Li, J., Yang, Y., He, H. and Guo, H.: 2020, Benefits of BDS$3 \mathrm{~B} 1 \mathrm{C} / \mathrm{B} 1 \mathrm{I} / \mathrm{B} 2 \mathrm{a}$ triple-frequency signals on precise positioning and ambiguity resolution. GPS Solut., 24, 4, 1-10. DOI: 10.1007/s10291-020-01016-8

Liu, W., Jin, X., Wu, M., Hu, J. and Wu, Y.: 2018, A new real-time cycle slip detection and repair method under high ionospheric activity for a triple-frequency GPS/BDS receiver. Sensors, 18, 2, 427. DOI: $10.3390 / \mathrm{s} 18020427$ 
Liu, Z.: 2011, A new automated cycle slip detection and repair method for a single dual-frequency GPS receiver. J. Geod., 85, 3, 171-183. DOI: $10.1007 / \mathrm{s} 00190-010-0426-y$

Melbourne, W.: 1985, The case for ranging in GPS-based geodetic systems. Proc. 1st International Symposium on Precise Positioning with the Global Positioning System, Rockville, 373-386.

Qian, N., Gao, J., Li, Z., Li, F. and Pan, C: 2020, GPS/BDS triple-frequency cycle slip detection and repair algorithm based on adaptive detection threshold and FNN-Derived ionospheric delay compensation. Acta Geodyn. Geomater., 17, 2, 141-157. DOI: 10.13168/AGG.2020.0010

Shi, J., Huang, Y. and Ouyang, C.: 2019, A GPS relative positioning quality control algorithm considering both code and phase observation errors. J. Geod., 93, 9, 1419-1433. DOI: $10.1007 / \mathrm{s} 00190-019-01254-\mathrm{w}$

Shi, J., Ouyang, C., Huang, Y. and Peng, W.: 2020, Assessment of BDS-3 global positioning service: Ephemeris, SPP, PPP, RTK, and new signal. GPS Solut., 24, 3, 1-14. DOI : 10.1007/s10291-020-00995-y

$\mathrm{Su}, \mathrm{K}$. and Jin, S.: 2019, Triple-frequency carrier phase precise time and frequency transfer models for BDS3. GPS Solut., 23, 3, 1-12. DOI: $10.1007 / \mathrm{s} 10291-019-0879-2$

Tang, L., Zheng, K. and Li, X.: 2017, Analysis of geometryfree residuals in case of traveling ionosphere disturbances and their impact cycle slip detection. GPS Solut., 21, 3, 1221-1226. DOI: 10.1007/s10291-0170606-9

Wang, Y., Zhang, K., Liu, W., Li, Z. and Wang, F.: 2019, Real-time quadruple-frequency cycle slip detection and repair algorithm based on the four chosen linear combinations. IEEE Access, 7, 154697-154710. DOI: 10.1109/ACCESS.2019.2949265

Wübbena, G.: 1985, Software developments for geodetic positioning with GPS using TI 4100 code and carrier measurements. Proc. 1st International Symposium on Precise Positioning with the Global Positioning System, Rockville, 403-412.

Yang, Y., Gao, W., Guo, S., Mao, Y. and Yang, Y.: 2019, Introduction to BeiDou-3 navigation satellite system. Navig. J. Inst. Navig., 66, 1, 7-18. DOI:10.1002/navi.291

Yang, Y., Mao, Y. and Sun, B.: 2020, Basic performance and future developments of BeiDou global navigation satellite system. Satell. Navig., 1, 1, 1-8. DOI: 10.1186/s43020-019-0006-0

Yang, Y., Xu, Y., Li, J. and Yang, C.: 2018, Progress and performance evaluation of BeiDou global navigation satellite system: Data analysis based on BDS-3 demonstration system. Sci. China Earth Sci., 61, 5, 614-624. DOI: 10.1007/s11430-017-9186-9
Yao, Y.F., Gao, J.X., Wang, J., Hu, H. and Li, Z.K.: 2016, Real-time cycle-slip detection and repair for BeiDou triple-frequency undifferenced observations. Surv. Rev., 48, 350, 367-375. DOI: $10.1080 / 00396265.2015 .1133518$

Yao, Y. and Wang, S.: 2020, Effect of selection of combined observations on cycle-slip repair success rate for BDS triple-frequency signals. Adv. Space Res., 66, 12, 2914-2925. DOI: 10.1016/j.asr.2020.03.013

Yao, Y., Cao, X., Chang, G. and Gao, H.: 2019, Accuracy analysis of ionospheric prediction models for repairing cycle slips for beidou triple-frequency observations. J. Navig., 72, 6, 1565-1584. DOI: $10.1017 / \mathrm{S} 0373463319000456$

Yao, Y., Zhang, X. and Cao, X.: 2019, An efficient cycleslip repair model with high success rate for BDS triplefrequency observations. IEEE Access, 7, 142750142761. DOI: 10.1109/ACCESS.2019.2944436

Zangeneh-Nejad, F., Amiri-Simkooei, A.R., Sharifi, M.A. and Asgari, J.: 2017, Cycle slip detection and repair of undifferenced single-frequency GPS carrier phase observations. GPS Solut., 21, 4, 1593-1603. DOI: 10.1007/s10291-017-0633-6

Zhang, Z., Li, B., Nie, L., Wei, C., Jia, S. and Jiang, S.: 2019, Initial assessment of BeiDou-3 global navigation satellite system: signal quality, RTK and PPP. GPS Solut., 23, 4, 1-12. DOI : 10.1007/s10291-019-0905-4

Zhang, X. and Li, P.: 2016, Benefits of the third frequency signal on cycle slip correction. GPS Solut., 20, 3, 451460. DOI: $10.1007 / \mathrm{s} 10291-015-0456-2$

Zhao, Q., Sun, B., Dai, Z., Hu, Z., Shi, C. and Liu, J.: 2015, Real-time detection and repair of cycle slips in triplefrequency GNSS measurements. GPS Solut., 19, 3, 381-391. DOI: 10.1007/s10291-014-0396-2

Zeng, T., Sui, L., Xu, Y., Jia, X., Xiao, G., Tian, Y. and Zhang, Q.: 2018, Real-time triple-frequency cycle slip detection and repair method under ionospheric disturbance validated with BDS data. GPS Solut., 22, 3,1-13. DOI: 10.1007/s10291-018-0727-9

Zumberge, J.F., Heflin, M.B., Jefferson, D.C., Watkins, M.M. and Webb, F.H.: 1997, Precise point positioning for the efficient and robust analysis of GPS data from large networks. J. Geophys. Res., Solid Earth, 102, B3, 5005-5017. DOI: 10.1029/96JB03860 